\title{
Do Sovereign Credit Default Swaps Represent a Clean Measure of Sovereign Default Risk? A Factor Model Approach
}

\author{
Saad Badaoui*, Lara Cathcart*, Lina El-Jahel*
}

January 14, 2012

(Preliminary Version- Please do not quote without permission)

\begin{abstract}
In this study, we use a factor model in order to decompose CDS spreads into default, liquidity, systematic liquidity and correlation components. By calibrating the model to sovereign CDSs and bonds we are able to present better decomposition and more accurate measure of spread components. Our analysis reveals that sovereign CDS spreads are highly impacted by liquidity risk (i.e $50 \%$ of default risk and $49.91 \%$ of liquidity risk) and that sovereign bond spreads are less subject to liquidity frictions and therefore represent a better poxy for sovereign default risk (i.e $97.08 \%$ of default risk and $1.73 \%$ of liquidity risk). Furthermore, our model extension enables us to directly study the effect of systematic liquidity and flight-to-liquidity risks on bond and CDS spreads through the factor sensitivity matrix. Although these risks do have an influence on the default intensity, the magnitude of their impact is small and therefore they do not contribute significantly to spread movements.
\end{abstract}

EFM Classification: 340, 360, 440, 450, 620

Keywords: Sovereign CDS spreads, Default and Liquidity Intensities, Grid Search Method and Exponential Affine Models.

*Imperial College Business School, Imperial College London, South Kensington Campus, SW7 2AZ United Kingdom. Tel: 44 (0)20 7594 9126. email: saad.badaoui07@imperial.ac.uk, 1.cathcart@imperial.ac.uk and1.el-jahel@imperial.ac.uk. 


\section{Introduction and Literature Review:}

\subsection{Introduction}

"The five-year bond issue priced in January 2010 had widened enormously in part because the situation was exacerbated by the use of CDS and the aggressive trading by certain quarters in the markets”. Petros Christodoulou, Head of the Greek Public Debt Management Agency

Understanding the determinants of sovereign CDS spreads is becoming increasingly important not only for practitioners but also for policy makers. According to the BIS quarterly Review (December 2010) approximately $80 \%$ of the CDS market relates to corporate issuers and $20 \%$ to sovereign entities. However the sovereign CDS market has recorded the strongest growth these recent years showing 50\% increase in the gross positions (from 2009 to 2010).

The credit market has mainly been criticized for being the trigger of the financial crisis especially the sovereign crisis and central banks are put under pressure to enforce tough regulations. It is argued that excessive trading of sovereign CDSs moved bond yields away from their fundamental values and sent false signals of weak creditworthiness of the Greek government. Suggestions were made about banning speculative trading, however there is no clear evidence of its negative effects on spread movements.

The question of whether CDS spreads fairly represents the probability of default remains ambiguous. Calice, Chen and Williams (2011) emphasize that the manipulation of market liquidity is often the primary mechanism through which speculative attacks are channeled. Therefore, if credit markets are subject to speculation, it is very relevant to thoroughly study the components of sovereign CDS spreads and quantify how much of it account for default and liquidity risks. In a recent study, Tang and Yan (2010) examine the demand driven price pressure on corporate CDS spreads. By constructing a variable that measure the net trade imbalance called the net buying interest (NBI), the authors are able to show that there is a strong relation between changes in CDS spreads and NBI and that this latter contains information on the future changes of CDS spreads. In fact, this finding supports the idea that excessive trading in CDSs can have a significant impact on the spreads. For example, in the sovereign CDS case, default is very rare and most of time when a country is in financial turmoil, other countries interfere to propose a bail-out package. If market participants know that default is highly unlikely, this might give them an incentive to speculate and sell CDS contracts in order to get the premium without fearing any default. If the sell-side is stronger than the buy-side then we have a trade imbalance that might affect CDS spreads even though the pure default risk hasn't changed; this proves that liquidity has a strong pricing power and it is therefore important to investigate it. The objective of this paper 
is to quantify the size of liquidity component in the sovereign CDS spreads and to provide a detailed decomposition of the spreads by using information from both CDS and bond markets.

In fact, few papers tried to decompose the sovereign CDS spreads in order to isolate the default risk from the risk premium. Longstaff et al (2011) found that a third of the sovereign CDS spreads is attributable to the distress risk premium. Remonola et al (2008) show that jump-at-default risk is priced in the sovereign CDS spreads without quantifying the magnitude of this risk premia. In the bond literature there are papers that study credit and liquidity risk effect on sovereign bond yields such as Codogno, Favero and Missale (2003), Geyer, Kossmeier and Pichler (2004), Beber, Brandt and Kavajecz (2009), Favero, Pagano and Thadden (2010), Schwarz (2010) and Monfort and Renne (2011). Although these papers disagree in their results they do agree that liquidity risk is present in the sovereign bond yields. We differ from the previous studies by using information from both CDS and bond markets to do our decomposition because both assets are driven by the same default risk and their liquidity risks are highly correlated (Pu (2010) and Calice, Vhen and Williams (2011)). In fact, by jointly calibrating the model using both CDS and bond data we are able to use a large amount of information on sovereign default risk and thus present a better decomposition and estimate the components more precisely.

In order to do this analysis, we extend the factor model of Buhler and Trapp (2010)-BT thereafter. BT framework allows us to jointly estimate default risk using information from both bond and CDS markets and measure the correlation components between default and liquidity risks. Favero, Pagano and Thadden (2010) argue that an estimation that ignores the interaction effect between the aggregate default and liquidity risks may underestimate the impact of liquidity on prices. The fact that our model enables us to estimate the correlation parameters between default risk and other risk premia is one of the key differences between our study and that of Longstaff et al (2011) and Remonola et al (2008).

Our results reveal that default risk represents on average $97.08 \%$ of the bond spreads, liquidity risk $1.73 \%$ and the correlation risk $0.93 \%$. On the CDS side we find that, on average, default risk account for $50 \%$ of the spreads, liquidity risk for $49.91 \%$ and correlation risk for $0.09 \%$.

Our results indicate that sovereign CDS spreads are highly impacted by liquidity risk and that sovereign bond spreads are less subject to liquidity frictions and therefore represent a better poxy for sovereign default risk. Secondly, although sovereign bond and CDS markets are subject to global liquidity shocks, the spreads do not seem to be heavily impacted by systematic liquidity and/or flightto-liquidity risks. Our paper has important implications for practitioners and policy makers and enhances our understanding of the main drivers of sovereign bonds and most importantly sovereign CDS spreads because if high CDS spreads imply high liquidity risk instead of high default risk then central banks could take appropriate measures to monitor liquidity risk embedded in the spreads in order to avoid situations similar to the one of Greece.

To the best of our knowledge this paper provides several contributions to the literature (1) we 
provide the first study that attempts to quantify liquidity risk premium in the sovereign CDS market (2) our model extension enables us to study the joint effect of systematic liquidity risk and flight-toliquidity in both sovereign bond and CDS markets, an analysis that hasn't been accomplished yet (3) finally, by studying the correlation premia between default and liquidity risks we are able to provide better decomposition than the one provided by Longstaff et al (2011) and Remonola et al (2008).

In the following subsections, we discuss the related literature and the motivation behind our model extension. In Section 2, 3 and 4, we present in more details the model extension, introduce our data and describe the calibration procedure respectively. In Section 5 and 6, we discuss the results for each rating. Section 7 , we carry out a time series analysis on the calibrated intensities. Finally, Section 8 we present concluding remarks of our study.

\subsection{Related Literature:}

A large amount of literature have tried to explain the components of corporate bond yields (Longstaff and Schwartz (1995), Colin-Dufresne, Goldstein and Martin (2001), Huang and Huang (2003), Driessen (2005), Longstaff, Mithal and Neis (2005), Han and Zhou (2007), Mahanti, Nashikar and Subrahmanyam (2007), Lin, Lui and $\mathrm{Wu}$ (2009) and many others). A consensus from these studies is that corporate bond yields are heavily influenced by other factors than credit risk, such as liquidity risk, tax and macroeconomic variables. Longstaff et al (2005) present the first study that uses CDS spreads to decompose bond yields and find that the non-default component is time-varying and heavily influenced by bond liquidity factors. In the same spirit, Han and Zhou (2007) study the corporate bond yields using the term structure of CDS spreads and find that the non-default component fluctuates with macroeconomic variables and stock market liquidity.

The bond literature also tried to measure the non-default component of the sovereign bond yields. Codogno, Favero and Missale (2003) study the determinants of the euro-area differentials with both monthly and daily data and found that international factors rather than domestic ones have strong explanatory power while liquidity plays a role for few countries. Geyer, Kossmeier and Pichler (2004), using a CIR model, find that bond yields for EMU countries are mainly explained by a global risk factor (i.e corporate bond risk measured by the difference between corporate bonds and Bund yield) and that liquidity does not have any impact. Beber, Brandt and Kavajecz (2009) study the components of sovereign bond yields and use the CDS data for European sovereigns to measure the effect of flightto-quality and flight-to-liquidity. They shown that credit and liquidity risks are positively correlated and that credit risk represents the majority of the sovereign bond yields. Favero, Pagano and Thadden (2010) also explore the determinants of the sovereign bond yields by taking into account the interaction effect between aggregate default and liquidity risks, they show that default risk explains the majority of the sovereign bond yields and that liquidity plays a minor role. Schwarz (2010) investigate the 
effect of liquidity risk on sovereign bond yields and found that market liquidity explains $68 \%$ of the widening of sovereign bond spreads, this value is surprisingly high and is in sharp contrast with what has been documented in the literature. Panyanukul (2010) examines the effects of liquidity on sovereign bond returns and show that the combined effect of liquidity level and liquidity risks can explain roughly $1 \%$ of extra yield spreads for the countries that have higher liquidity betas. Finally, Monfort and Renne (2011) provide and estimate an affine term structure model that directly measures liquidity and credit risks in the term structure of euro bonds. They find that the liquidity part of the spreads is less important than the credit related one even though liquidity effect is non trivial.

In fact, the studies mentioned above consider that CDS spreads are not subject to liquidity risk, however there is a growing literature that acknowledges the importance of liquidity in the CDS market. Berndt et al (2005) and Pan and Singleton (2008) show that corporate and sovereign CDS spreads are too high to account only for default risk, they suggested a liquidity factor as possible component to represent the non-default part. Tang and Yan (2007) studied empirically the effect of liquidity and liquidity risk on corporate CDS spreads. They find that liquidity plays non-trivial role in corporate CDS spreads. Meng and Gwilym (2008) analyse CDS liquidity with a specific focus on how bidask spreads of individuals CDSs (corporate and sovereigns) are affected by the characteristics of the contracts such as demand supply pressure, inventory risks and clientele effects. Although this study is very similar in spirit to Tang and Yang (2007), it differs by having a focus on the determinants of liquidity proxied by bid-ask spreads. The other difference is related to the data used, Tang and Yan (2006) focus only on corporate entities while Meng and Gwinlym (2008) pools a large dataset together where sovereign entities represent less than $20 \%$ of the sample. Bongaerts, De Jong and Driessen (2010) examine the role of liquidity in corporate CDS spreads, they extend the model of Acharya and Pedersen (2005) and find that expected liquidity exceeds the liquidity risk effect. Qui and Yu (2011) provide the first study that explores the determinants of endogenous liquidity provision in the CDS market. The authors treat liquidity as being endogenously determined by information heterogeneity and frequency of uninformed trading. One of their main findings suggests that endogenous liquidity provision in the CDS spreads is an increasing function of the level of information heterogeneity present in the market. They empirically prove that the information flow is increasing with the number of CDS quote providers and this is particularly relevant under unfavorable credit conditions. Finally, they report a mixed result by arguing that the degree of information heterogeneity plays a capital role on how liquidity affects CDS spreads.

All these papers showed that liquidity plays an important role in CDS spreads which lead other studies to extend the model of Longstaff, Mithal and Neis (2005) (LMN-thereafter) to account for CDS liquidity in order to measure the non-default component of corporate bond yields. Lin et al (2009) extend the LMN model to incorporate CDS liquidity effect and quantify the size of liquidity component in both corporate CDS and bond spreads. They are able to show that liquidity represents 
on average $13 \%$ of the CDS spreads. Secondly, they provide the evidence that on average corporate bond yield are composed of $47 \%$ of default risk, $30 \%$ of taxes and $23 \%$ of liquidity factor. Buhler and Trapp (2010) also extend the LMN model but differ from Lin et al (2009) by taking into account the correlation effect between credit and liquidity risks and between bond and CDS liquidity risks. Therefore by calibrating their model to both CDS and bond data they are are able to capture important dynamics at cross-sectional and time-series level. Overall, they show that $60 \%$ of bond spreads are to due to default risk, $35 \%$ to liquidity risk and $5 \%$ to correlation between credit and liquidity risks. For the CDS spreads, credit risk represents $95 \%$, liquidity $4 \%$ and correlation $1 \%$.

On the sovereign CDS side, few papers tried to isolate default risk from the risk premium. Longstaff et al (2011) decompose the sovereign CDS spreads into default risk and risk premium components. They view the risk premium as a compensation to the unpredictable changes in default arrival rate i.e "distress" risk. The authors quantify the risk premium by taking the difference between the CDS theoretical values under the risk neutral and physical measures and find that on average distress risk represents a third of the sovereign CDS spreads. Remonola et al (2008) use a dynamic model to analyse sovereign CDS spreads and find that they are composed of expected losses from default (i.e default component) and risk premia required by investors as a compensation for default risk. In fact, the studies of Longstaff et al (2011) and Remonola et al (2008) are similar in spirit while the former focuses on "distress" risk, the latter discusses the "jump-at-default" risk. Our paper differs from the previous literature by not only focusing on the effect of instrument-specific liquidity and systematic liquidity risk but also by using information from both bonds and CDSs to carry out the analysis.

Decomposing sovereign CDS spreads using information from both bonds and CDSs is essential in many aspects. Typically both markets are highly integrated because they share the same default risk. Secondly there is large literature showing that bond and CDS liquidity risks are highly correlated. Pu (2010) explores the properties of liquidity measures across the corporate bond and the CDS markets. The author provides the evidence that there is a strong commonality across all the constructed liquidity measures and shows that a substantial amount of credit spreads could be explained by liquidity common factors. Calice, Vhen and Williams (2011) analyse the potential liquidity spill-over between sovereign bond and CDS markets during the European crisis in 2010. The authors report three important findings. First, when sovereign bond liquidity dries up, CDS liquidity increases significantly with spreads bids and spreads asked reaching a one-to-one ratio. Moreover, the paper provides the evidence of a strong spill-over of liquidity from the CDS to the bond spreads. Finally, they show that, prior to the crisis, bond yields determined CDS spreads, however during the crisis the relationship inverted with CDS spreads taking the lead over bond yields. Amadei et al (2011) study the issues related to the European sovereign CDS market and its relation with the bond market. They find that, during the recent crisis, bond-CDS arbitrage relation became infeasible. However when the sovereign bond market is less liquid, CDSs have the leading role in terms of price discovery. Furthermore, the authors 
find no clear evidence that speculation has a direct effect on sovereign bond prices, therefore any regulatory measure taken against speculation must be assessed with caution because this might hamper the functioning of the sovereign bond market. Ismailescu and Philips (2011) investigate the impact of CDS trading initiation on sovereign bonds from the perspective of market completeness, price discovery and borrowing costs. The authors report that CDSs are not redundant assets and contribute to an incremental increase of pricing information of about $67 \%$. However, the authors show that this result differs at cross sectional level. Countries with high openness do not benefit as much from price informativeness gains. Finally, according to the paper, CDS introduction appears to provide a liquidity service to investment grade sovereigns resulting in lower borrowing costs. Arce et al (2011) analyse the relationship between sovereign bond and CDS spreads from three angles. Firstly, the authors find that there is a persistent deviation from the parity relationship between CDS and bond spreads and that this deviation accelerated during the subprime crisis. Secondly, they find that counterparty risk indicators, funding costs and liquidity have significant impact on CDS-bond basis. Moreover, the authors analyse what market leads the pricing discovery by using the approach of Gonzalo and Granger (1995) and conclude that global risk aversion, funding costs, market liquidity and debt volume are all playing an important role in determining which market leads the discovery.

All these papers emphasize that bonds and CDSs share common features hence the importance of doing a joint calibration in order to present better decomposition of the spread components. In this following subsection, we discuss the BT model extension.

\subsection{Motivation Behind the BT Model Extension: Systematic Liquidity Risk and Flight- To-Liquidity}

The sovereign CDS market is subject to a high level of commonality. Longstaff et al (2010) documented that the first principal component accounts for $64 \%$ of the variation in sovereign CDS spreads, this percentage reaches $75 \%$ when the sample period is restricted to the crisis. Pan and Singleton (2008) investigate the default intensity and the recovery rate using the term structure of CDS spreads and show that the first principal component captures $96 \%$ of the variation over-time of the term structure. Finally, Augustin and Tedongap (2010) develop a consumption based model in order to link the sovereign credit risk premia to consumption growth forecast, macroeconomic uncertainty and investors preferences. By using a PCA, they find that three factors are sufficient to explain $95 \%$ of the commonality. All these papers emphasize that commonality is an important source of risk because it may facilitate contagion between countries. For example, if a country experiences an increase in its default/liquidity risk it highly likely that other markets might be affected. In line with this, Pan and Singleton (2008) demonstrate that during some sub-periods a significant part of the co-movement of the term structure of sovereign CDS spreads across countries is caused by changes of investors 
risk appetite towards credit exposures rather than a reassessment of the creditworthiness of sovereign economies.

This important finding implies that in light with the recent financial crisis it is highly likely that a global risk aversion towards certain region of the world may create liquidity shocks, which consist of an excessive demand or supply of CDSs of few countries, which may in turn affect CDS market liquidity. Therefore, if the sovereign CDS market is subject to commonality risk ${ }^{1}$ as the literature showed, then it is important to incorporate the systematic liquidity risk or market liquidity as an additional factor in the BT model.

Finally, since our decomposition also deals with bond spreads, it is essential to mention bond market liquidity risk and its impact on CDS spreads. Beber et al (2009) showed that sovereign bond market are subject to flight-to-liquidity risk during crisis time which means that, in case of default, defaultable bond liquidity might be exacerbated by bond market liquidity. This implies that not only instrument specific liquidity but also sovereign bond market liquidity might put pressure on CDS defaultable leg.

In summary, we have two sources of risk that may have a substantial influence on sovereign CDSs but not taken into account in BT model. Therefore, by extending the original setting we aim to provide a comprehensive framework that contains the major sources of risk that could affect both CDS and bond spreads. In the following section, we will present our extension in some details.

\section{Model Defintion: The Sovereign Market Case}

In our model, we choose the default-free zero coupon bond as "liquidity numeraire" and depart from the assumption that the risk-free rate is independent from the default and the liquidity intensities (Longstaff et al (2005), Pan and Singleton (2008)). Therefore, the risk structure of our model is

\footnotetext{
${ }^{1}$ On top of commonality risk, there is another element that could ease the contagion effect in the sovereign CDS market which is the banking crisis. A recent report by BIS (December 2008) advances that the widening of sovereign credit default swaps is caused by the bank rescue packages that significantly increased the risk in the government balance sheets. The report states that:

"The scope and magnitude of the bank rescue packages also meant that significant risks had been transferred onto government balance sheets. This was particularly apparent in the market for CDS referencing sovereigns involved either in large individual bank rescues or in broad-based support packages for the financial sector, including the United States. While such CDS were thinly traded prior to the announced rescue packages, spreads widened suddenly on increased demand for credit protection, while corresponding financial sector spreads tightened"

These considerations make of the sovereign CDSs risky instruments because they are not only exposed to the country specific but also to the macroeconomic risks.
} 
composed of:

$$
D(t, \tau)=\exp \left(-\int_{0}^{\tau} r_{s} d s\right)
$$

where $D(t, \tau)$ is the risk-free discount factor,

$$
P(t, \tau)=\exp \left(-\int_{0}^{\tau} \lambda_{s} d s\right)
$$

where $P(t, \tau)$ is the risk neutral default probability and

$$
L(t, \tau)=\exp \left(-\int_{0}^{\tau} \gamma_{s}^{l} d s\right)
$$

where $L(t, \tau)$ is the risk neutral liquidiy intensity. The subscript $l$ in the liquidity intensity $L(t, \tau)$ refers to either CDS or bond liquidity.

CDS spreads can be impacted by default risk, instrument-specific liquidity and possibly by liquidity changes in CDS and bond markets. Typically, high liquidity risk is accompanied by high bid-ask spreads and thus high CDS spreads. High liquidity risk increases the price of buying CDS protection because the ask quote has to compensate the CDS seller (i.e dealer) for the credit risk and the liquidity risk. On the other hand, high liquidity risk also reduces the price of selling CDS protection, the intuition is that CDS buyers (i.e dealer) will only be ready to buy the protection from investors at a cheap price (i.e low bid) because of high liquidity risk. Therefore, the bid-ask spread constitutes a hidden cost to market participants when they trade assets and we measure its effect with the following liquidity intensities $\gamma^{a s k}(t)$ and $\gamma^{b i d}(t)$.

In our setting, we make the assumption that systematic liquidity risk may inflate or deflate bid-ask spreads. Therefore one of the goals of our model is to measure how much extra effect can systematic liquidity risk have on the bid-ask spreads on top of the effect that is due to the instrument-specific liquidity described above. We thus add two liquidity intensities $\gamma^{\text {gcask }}(t)$ and $\gamma^{\text {gcbid }}(t)$ in order to measure the extra effect specific to the systematic liquidity risk. $\gamma^{\text {gcask }}(t)$ and $\gamma^{\text {gcbid }}(t)$ refer to global CDS ask and global CDS bid respectively and aim to capture the extra premium on bid and ask side of the CDS spreads. 
Concerning the bonds, we also try to capture the impact of bond liquidity $\gamma^{b}(t)$ and the risk of flight-to-liquidity $\gamma^{g b}(t)$ in the sovereign bond market. The intuiton is that a bond liquidity shock at global level might create extra frictions that are not captured by the standard bond liquidity discount factor $\gamma^{b}(t)$. In total we have seven factors $\left(\lambda(t), \gamma^{a s k}(t), \gamma^{b i d}(t), \gamma^{g c a s k}(t), \gamma^{g c b i d}(t), \gamma^{b}(t)\right.$ and $\left.\gamma^{g b}(t)\right)$ that could influence both CDS and bond spreads.

The structure of seven factor model can be summarized as follows:

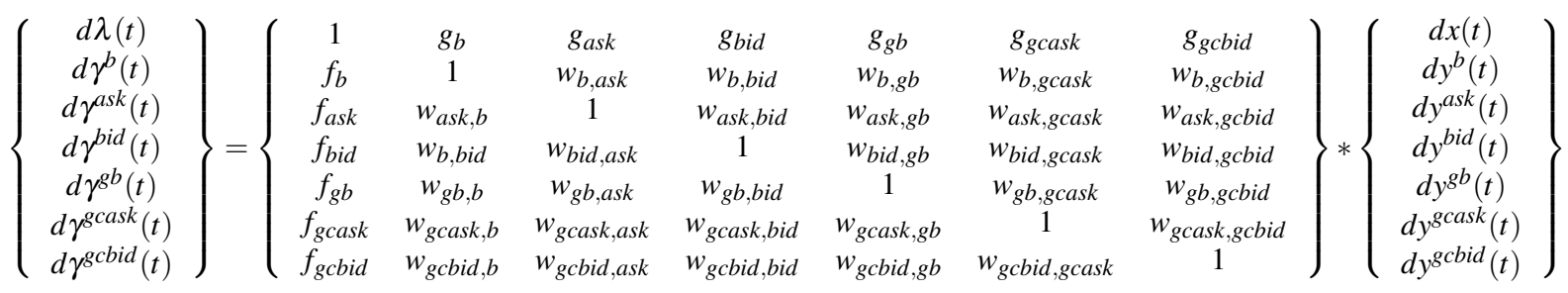

The left hand-side of the equation (4) represents the correlated intensities and the right-hand side the factor matrix multiplied by the pure intensities. One of the assumptions of our model is that the pure intensities $x(t)$ and $y^{l}(t)$, which represent pure default and liquidity risks, are not correlated neither at time-series nor at cross-sectional level which ensure their independence. On the other hand, the factor sensitivity matrix reflects the interactions between default risk, instrument-specific liquidity and market liquidity risks. For example, the default intensity $\lambda(t)$ can be written in the following form:

$\lambda(t)=x(t)+g_{b} * y^{b}(t)+g_{a s k} * y^{a s k}(t)+g_{b i d} * y^{b i d}(t)+g_{g b} * y^{g b}(t)+g_{\text {gcask }} * y^{\text {gcask }}(t)+g_{\text {gcbid }} * y^{\text {gcbid }}(t)$

This matricial approach will enable us to isolate the pure intensities from their correlation components and therefore present better decomposition of the CDS spreads than the one of Longstaff et al (2011) and Remonola et al (2008).

The parameter $f$ in the factor matrix represents the impact of liquidity risk on the pure default intensity $x, g$ corresponds to the impact of credit risk premia $\lambda$ on liquidity risk. A positive sign of $g$ is likely if high sovereign default risk increases liquidity risk in the bond market. In line with this, Favero, Pagano and Thadden (2010) find that there is a positive relationship between aggregate default and liquidity risks. $w$ captures the interactions between CDS and bond liquidity. Bonds and CDSs can be substitute to each other, in fact if there is high liquidity risk in the bond market investors will use 
CDSs as an alternative to take long (short) credit risk positions which might reduce CDS liquidity risk. On the other hand, if market participants use CDSs mainly to hedge their bond positions then high CDS liquidity risk may increase bond liquidity risk. This two way relationship causes liquidity spillover from one market to other. Furthermore, commonality in liquidity risk might make the spill-over effect higher which could in turn inflate the influence of $f_{\text {gcask }}, f_{\text {gcbid }}$ or $g_{\text {gcask }}, g_{\text {gcbid }}$.

We assume a CIR process for the pure default intensity in order to ensure that default arrival rate is always non-negative:

$$
d x=(\alpha-\beta * x(t)) * d t+\sigma \sqrt{x(t)} * d W^{\lambda}(t)
$$

Concerning the pure liquidity intensity, we follow the approach of Longstaff et al (2005) and assume a Gaussian process for $y^{l}$ in order to allow liquidity to take both positive and negative values:

$$
d y^{l}=\eta * d W^{l}(t)
$$

$W^{l}$ and $W^{\lambda}$ are independent Brownian motions specific to the liquidity and the default intensities respectively. $\alpha, \beta, \eta>0, \sigma>0$ represent the parameters specific to each intensity.

\subsection{Bond Market:}

In this subsection, we discuss how our model enters the pricing formula of the defaultable bond. We follow the result of Pan and Singleton (2008) and assume that the recovery $R$ is equal to $25 \%$ of the face value $F^{2}$. We also adopt the discrete time setting in order to match the coupon semi-annual payment date $t_{i}\left(t_{1}, t_{2}, . ., t_{10}\right)$. The price of the defaultable bond denoted as $C B(t)$ is the sum of expected semi-annual coupon bond weighted by the default probability and the bond liquidity discount factor. In this framework we assume that default can only happen at the payment date $t_{j}\left(t_{i}=t_{j}\right)$ and that recovery occurs the following day ${ }^{3}$. The last term of $C B(t)$ corresponds to the recovery after default has occurred and as the model shows the recovery can be significantly influenced by bond liquidity and bond market liquidity.

\footnotetext{
${ }^{2}$ Pan and Singleton (2008) study the recovery implicit in the term structure of sovereign CDS spreads and find that $25 \%$ of recovery is reasonable estimate, in line with market convention.

${ }^{3}$ Our model could be easily extended to allow for stochastic settlement times in case of a credit even. However since our framework is multi-dimensional we make this assumption in order to gain computational speed.
} 


$$
\begin{aligned}
C B(t)= & c * \sum_{i=1}^{n} D\left(t, t_{i}\right) * E_{t}\left[P\left(t, t_{i}\right) * L^{b}\left(t, t_{i}\right) * L^{g b}\left(t, t_{i}\right)\right]+ \\
& F * D\left(t, t_{n}\right) * E_{t}\left[P\left(t, t_{n}\right) * L^{b}\left(t, t_{n}\right) * L^{g b}\left(t, t_{n}\right)\right]+ \\
& R * F * \sum_{j=1}^{n} D\left(t, t_{j}\right) * E_{t}\left[\triangle P\left(t, t_{j}\right) * L^{b}\left(t, t_{j}\right) * L^{g b}\left(t, t_{j}\right)\right]
\end{aligned}
$$

$D\left(t, t_{i}\right)$ denotes the zero coupon bond, $L^{b}\left(t, t_{i}\right)$ the bond liquidity discount factor, $L^{g b}\left(t, t_{i}\right)$ the global bond liquidity discount factor, $P\left(t, t_{n}\right)$ the survival probability until time $t_{n}$ and $\triangle P\left(t, t_{j}\right)=P\left(t, t_{j-1}\right)-$ $P\left(t, t_{j}\right)$ the probability of surviving from time $t$ to time $t_{j-1}$ and defaulting between $t_{j-1}$ and $t_{j}$. All the expectations are taken under the risk neutral measure. The intuition behind the inclusion of $L^{g b}\left(t, t_{i}\right)$ is that bonds can be impacted by both their own liquidity risk and by the flight-to-liquidity in the sovereign bond market.

\subsection{CDS Market}

In the CDS contract, we have two legs: the fixed leg where CDS buyers pay semi-annual premium and the floating leg where CDS sellers receive the premium until default occurs. In the same way as for the bonds, we assume that default only happens at the payment dates, therefore we do not have any accrual payments. We also depart from the hypothesis that systematic liquidity risk constitutes a threat to CDS dealers. Because of commonality risk, liquidity risk spill-over can be significant and may affect CDS premia. The fixed leg is defined as follows:

$$
\operatorname{CDS}_{\text {fix }}^{\text {ask } / \text { bid }}(t)=s^{\text {ask } / \text { bid }} *\left(\sum_{i=1}^{n} D\left(t, t_{i}\right) * E_{t}\left[P\left(t, t_{i}\right) * L^{\text {ask } / \text { bid }}\left(t, t_{i}\right) * L^{\text {gcask } / g c b i d}\left(t, t_{i}\right)\right]\right)
$$

In the CDS ask/bid premia, we assume that spreads are not only influenced by default arrival rate $P\left(t, t_{i}\right)$ but also by liquidity. Therefore, $L^{\text {ask } / \text { bid }}\left(t, t_{i}\right)$ and $L^{\text {gcask } / g c b i d}\left(t, t_{i}\right)$ reflect the part of the premium that is attributed to instrument-specific liquidity and market liquidity respectively. If the CDS market is illiquid, this will exacerbate asset illiquidity therefore the protection seller is likely to in- 
crease the ask premium as a compensate for the additional risk that liquidity and market liquidity represent. In the same way, the protection buyer will lower the bid and buy the CDS at a discount.

The value of the floating leg is described as follows:

$$
\begin{aligned}
\operatorname{CDS}_{\text {float }}^{\text {ask } / \text { bid }}(t) & =F * \Sigma_{j=1}^{n} D\left(t, T_{j}\right) * E_{t}\left[\triangle P\left(t, t_{j}\right)\right] \\
& -R * D\left(t, t_{j}\right) * E_{t}\left[\triangle P\left(t, t_{j}\right) * L^{b}\left(t, t_{j}\right) * L^{g b}\left(t, t_{j}\right)\right]
\end{aligned}
$$

The equation implies that CDS sellers get the principal minus the recovery value of the bond which could be impacted by asset liquidity and flight-to-liquidity risk. The joint effect is valid whether the settlement is physical or cash because if the sovereign bond market is illiquid then the value of the cheapest bond will be affected.

Overall, the theoretical CDS and bond values for sovereigns should incorporate all these aspects in order to have a comprehensive picture of the different risks that could influence the spreads. In the appendix, we present the analytical solutions for equations (7), (8), and (9) using the exponential affine framework.

\section{Data and Descriptive statistics:}

We focus on emerging market countries to run our analysis since their sovereign debt is traded in dollar, this avoids any currency mismatch with the sovereign CDS currency. Our data spans from November 2005 to September 2010. For the term structure of the default free interest rate, we follow the approach of Longstaff et al (2005) and Pan and Singleton (2008) and use the Treasury Curve commonly known as CMT. We collect the data on a daily basis from the Federal Reserve H.15 statistical release for the constant maturity six-month, one, two, three, five, seven, ten, twenty and thirty year rates. We then use the cubic spline algorithm to infer the discount factors at semi-annual intervals.

We download bid, ask and mid of the 5-year CDS spreads on a daily basis from Datastream Reuters for the following countries: Chile, Korea, Mexico, Colombia, Peru, Brazil, Philippines, Indonesia, Turkey and Argentina. We pick a country only if it has at least two bond issues. The dataset contains a total of 38240 observations. For the purpose of our study, we also collect the current and the historical $\mathrm{S} \& \mathrm{P}$ credit rating from Datastream ${ }^{4}$. We assign a rating to a country by giving a number to each rating

\footnotetext{
${ }^{4}$ The S\&P historical ratings are not given at regular intervals but only when upgrades or downgrades occur.
} 
category and taking the average of the sample period (we round up if necessary). The ratings that we obtain are:

\begin{tabular}{|c|c|c|c|c|c|c|c|c|c|c|}
\cline { 2 - 10 } \multicolumn{1}{c|}{} & Arg & Bra & Chile & Indo & Philip & Tur & Peru & Colo & Mex & Kor \\
\hline Ratings & CCC/D & BBB & A & BB & BB & BB & BBB & BBB & BBB & A \\
\hline
\end{tabular}

This results in four rating categories A, BBB, BB and CCC. For each category we take the averages of the CDS mid quotes and the bond prices.

We obtain the bond data on a daily basis from Datastream. We collect the bid, ask and mid prices for each dollar denominated bond issued by the relevant country and focus only on fixed coupon bonds with no option embedded. The bid/ask are ICMA data, these are quotes provided by 30 investment banks. At the end of each working day, their closing bid and ask quotes are sent to Xtrakter where they are validated and processed to provide an average bid and ask for each security ${ }^{5}$.

In our implementation we are interested in the bid, ask and mid yields. Since they are not directly downloadable, we need to compute them in order to compare the 5-year bond spreads with the 5-year sovereign CDS spreads.

Sovereign bonds are semi-annual coupon bonds which means that for a bond price $P_{t}(C, N, \tau)$, the annual yield-to-maturity can be computed in the following way:

$$
P_{t}(C, N, \tau)=\sum_{i=1}^{N} \frac{C}{2}\left(1+\frac{y_{t}}{2}\right)^{-(\tau+0.5(i-1))}+\left(1+\frac{y_{t}}{2}\right)^{-(\tau+0.5(N-1))}
$$

where $C$ is the annual coupon rate, $N$ the number of remaining coupon payments and $\tau=\frac{T-t}{T}$ the ratio of the number of days until the next coupon payment to the number of days in the coupon period. Moreover, in this setting, we assume that the first coupon payment occurs in the first settlement date of our time series.

In order to compute sovereign bond spreads, we use the standard approach used in the literature. For each bond, we solve for the synthetic default-free bond with identical coupon and maturity as the defaultable bond. This is done in two steps, first we use the default free term structure of interest rate (i.e Treasury curve) and compute the price of a default-free coupon bond as the sum of discounted zero coupon rates multiplied by $C / 2$, then we solve for the default-free yield. Finally, we compute the bond spread by taking the difference between defaultable bond yields and synthetic default-free coupon bonds.

The last step consists of computing the five year bond spreads. In fact, it would be ideal if we

\footnotetext{
${ }^{5}$ Besides for Chile which has two bond issues, each country has large number of bonds. In fact, the diversity in the maturity dates will be useful in providing a good estimate for the 5 year bond spread.
} 
had a five year bond available at each time step in order to compare it with CDS spreads, however this is rarely the case. To address this problem the literature uses two methods either interpolation (Houweling and Vorst (2005)) or regression (Longstaff et al (2005)). We will use the interpolation method. Our dataset runs from 2005 to 2010, therefore the CDS maturity dates associated with our sample are from 2010 to 2015, hence we need bond with maturities from 2010 to 2015 to proxy the 5 year bond spreads. The countries that we picked do not always have a set of 6 bonds that mature exactly in 2010/2011/2012/2013/2014/2015, therefore when a bond maturity is missing we use as proxy a bond that has the closest maturity to the missing one. This methodology enables us to interpolate bond spreads to match CDS maturity.

Figure 1 shows the results for each rating class. The figures show that credit and CDS spreads for Rating A, BBB and BB track each other very closely although it seems that on average credit spreads are slightly higher than CDS spreads ${ }^{6}$.

\section{Calibration Procedure: Grid Search Method}

We calibrate the model to bond and CDS data for the following ratings: A, BBB, BB and CCC. Our calibration procedure is similar in spirit to Buhler and Trapp (2010), however since our model involves many parameters it is worth discussing in details the calibration and the different robustness checks carried throught the analysis. As mentioned before, we assume a CIR process for default arrival rate and a Gaussian process for liquidity intensities, this gives us a total of 9 parameters $\left(\mu, \beta, \sigma, \eta^{b}\right.$, $\left.\eta^{a s k}, \eta^{b i d}, \eta^{g b}, \eta^{\text {gcask }}, \eta^{\text {gcbid }}\right)$.

- We initialize a 9-dimensional grid for the drift and the diffusion parameters listed above. $j$ represents the grid number and $i$ the grid point in the grid $j$.

(a) The initialized vector $\left(\mu_{i j}, \beta_{i j}, \sigma_{i j}, \eta_{i j}^{b}, \eta_{i j}^{a s k}, \eta_{i j}^{b i d}, \eta_{i j}^{g b}, \eta_{i j}^{g c a s k}, \eta_{i j}^{g c b i d}\right)$ defines the parameters in each grid point $i$ in grid $j$.

(b) In each grid point $i$, we initialize the factor matrix $H_{i j k}$ where $k$ counts the number of iterations. $k$ will be different across the ratings.

(c) The calibration is done at cross-sectional level. Assuming that the initialized parameters in step (a) are true, for each time $t$ (where $t=1,2, \ldots ., T$ ) we numerically specify

\footnotetext{
${ }^{6}$ Rating CCC exhibits different results as it seems that bond spreads are a lot higher than CDS spreads.
} 
the parameters $\left(\lambda_{i j}, \gamma_{i j}^{b}, \gamma_{i j}^{a s k}, \gamma_{i j}^{b i d}, \gamma_{i j}^{g b}, \gamma_{i j}^{g c a s k}, \gamma_{i j}^{g c b i d}\right)(t)$ that minimize the sum of squared differences between the theoretical values and the observed prices (i.e CDS spreads and bond prices). Step (c) is performed by assuming $H_{i j k}$ to be an identity matrix, this leads to a one-to-one relationship between the correlated and the independent intensities.

$$
\left(\hat{\lambda}_{i j}, \hat{\gamma}_{i j}^{b}, \hat{\gamma}_{i j}^{a s k}, \hat{\gamma}_{i j}^{b i d}, \hat{\gamma}_{i j}^{g b}, \hat{\gamma}_{i j}^{\text {gcask }}, \hat{\gamma}_{i j}^{\text {gcbid }}\right)(t)=\operatorname{argmin} \Sigma_{n=1}^{N}\left(P_{n}^{\text {mod }}-P_{n}^{o b s}\right)^{2}
$$

where $P_{n}^{\text {mod }}$ represents the model price, $P_{n}^{\text {obs }}$ the observed values and $n$ the number of cross-sectional units.

(d) In order to determine the true factor matrix $H_{i j k}$, we need to minimize the "elementwise-sum" of the squared differences between the assumed latent factors in step(a) and the empirical variance, covariance and autocovariance. We denote this sum as $M_{i j k}\left(H_{i j k}\right)$. (e) To minimize $M_{i j k}\left(H_{i j k}\right)$ we need to numerically change the parameters of $H_{i j k}$ until $M_{i j k}$ converges. In order to perform this task we use an unconstrained non-linear optimization procedure. However, due to the high number of parameters in the factor matrix, we try many minimizations with different guessed values in order to compare the outputs and ensure that the global minimum is picked. We managed to minimize $M_{i j k}$ and reach a value of at least 0.001 for all the ratings. We also do a robustness check using another powerful optimization package ${ }^{7}$.

$$
\hat{H}_{i j k}=M_{i j k}\left(H_{i j k}\right)
$$

(f) We use the true factor matrix $\hat{H}_{i j k^{\text {opt }}}$ and the new intensities

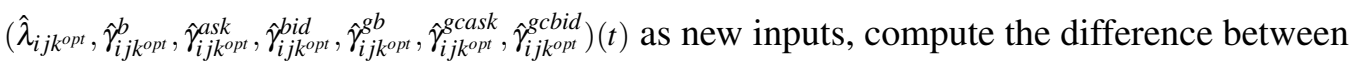
the theoretical and observed values and finally sum the differences across the time series.

$$
S_{i j}=\Sigma_{t=1}^{T} \Sigma_{n=1}^{N}\left(P_{n}^{\bmod }-P_{n}^{o b s}\right)^{2}
$$

We do the same operation across each grid point $i$ in grid $j$ and then take the minimum value of grid $j^{8}$.

$$
S_{j}^{o p t}=\min \left\{S_{1, j}, S_{2, j} \ldots \ldots \ldots, S_{I, j}\right\}
$$

\footnotetext{
${ }^{7}$ As robustness check, we use Mark Schmidt optimization toolbox minFunc. minFunc is a Matlab function for unconstrained optimization of differentiable real-valued multivariate functions using line-search methods. It can optimize problems with large number of variables.

${ }^{8}$ In order to use a grid method it is necessary to pick trial values. Therefore, we first estimate the model few times with different values, then we pick the best ones and create a grid around it.
} 
- We pick the minimum value of step(f), use it as a finer local grid and move to the second grid. We do the same analysis until we reach grid 9. This method enables us to pick the minimum value for each grid and ensure that the function reaches a global minimum.

- As a robustness check we do a constrained optimization by changing $\left(\mu_{i j}, \beta_{i j}, \sigma_{i j}, \eta_{i j}^{b}, \eta_{i j}^{a s k}, \eta_{i j}^{b i d}, \eta_{i j}^{g b}, \eta_{i j}^{g c a s k}, \eta_{i j}^{g c b i d}\right)$. Each parameter change requires us to return to step (a) and reestimate the model. This procedure ensure that the results are robust and that the functions are minimized globally.

We fit very well the model to all the rating with a small error. For Rating BBB, we obtain an average error of $7.1 \%$ for CDS bid and ask spreads and $1.53 \%$ for bond prices. For Rating CCC, we have an average error of $4.78 \%$ for CDS bid and ask spreads and $0.017 \%$ for bond prices. For Rating A, we document an average error of $0.9 \%$ for CDS bid and ask spreads and $2.72 \%$ for bond prices. Finally Rating BB shows an average error of $6.1 \%$ for CDS bid and ask spreads and $0.002 \%$ for bond prices.

\section{Measuring Credit Risk, Liquidity, Systematic Liquidity Risk and Cor- relation Premium:}

\subsection{Description of the time series properties:}

In Figure 2, we plot the pure intensities retrieved from the calibration procedure and discuss the time series properties. Table 2 presents the descriptive statistics of the estimated intensities and shows that default intensities are positive across all the ratings however liquidity intensities have both negative and positive values. The signs are consistent with the assumptions made on the processes driving the intensities.

Figure 2 shows that pure default risk increases during the crisis period across all ratings, however the magnitude of the jump is the lowest for rating $\mathrm{A}$ this is consistent with the fact that rating $\mathrm{A}$ is the safest rating and therefore the least impacted by the financial crisis. On the other hand rating CCC shows a more volatile credit risk. Overall, the graphs show that CDS liquidity and CDS market liquidity risk move in the same direction, this supports the idea that liquidity risk in the CDS market shares common factors consistent with Longstaff et al (2010). According to the graphs, the volatility of the liquidity during crisis increases as the rating decreases. The lowest liquidity value for Rating BBB is around -0.74 and the highest one is around -0.64 . For CCC rating the lowest value is -0.8 and the highest reaches -0.4 which indicates that liquidity risk can significantly increase for this rating. Moreover, bond liquidity and bond market liquidity behave in the same way as CDS liquidity risk, this is again support the idea that rating $\mathrm{CCC}$ is the most vulnerable to liquidity risk ${ }^{9}$.

\footnotetext{
${ }^{9}$ Rating A displays different results as bond liquidity and bond market liquidity risk have opposite signs and low volatility
} 


\subsection{Estimation Procedure:}

In this subsection, we plug back the calibrated intensities into the CDS and the bond pricing formula (equation (7), (8) and (9)) and decompose the spreads in order to retrieve the default and the nondefault components of each asset.

We decompose the credit spreads into a pure credit risk component $b d$, a pure liquidity component $b l$, a pure global liquidity component $b l g$, a correlation component $b c$ and finally a global correlation component $b c g$. In the same spirit as $\mathrm{BT}, b d, b l$ and $b l g$ correspond to the bond spread if only credit risk, liquidity and market liquidity are priced, in that case the factor sensitivities are equal to 0 ( $f=$ $g=w=0)$ and pure and correlated intensities coincide. $b c$ corresponds to the bond spreads resulting from the correlation effect between credit and liquidity risk. Finally, $b c g$ measures the full bond spread that contains the correlations between credit, liquidity and market liquidity risks $(f \neq g \neq w \neq 0)$. The sum of the five components mentioned above correspond to the full bond spreads with maturity and payment dates equal to those of the CDSs.

Likewise, we disentangle the CDS spreads into a pure credit risk component $s d g$, a pure liquidity component $s l$, a pure global liquidity component $s l g$, a correlation component $s c$ and global correlation component $s c g$. $s d g$ is measured by the default free rate, default probability, bond liquidity and global bond liquidity risk. Therefore $s d g$ corresponds to the theoretical mid spread without CDS liquidity effect. In a second step, we consider the CDS liquidity $s l$ and the CDS market liquidity $s l g$ without taking into account correlation. In the last step we consider the correlation of credit risk and liquidity $(s c)$ and the correlation of credit risk, liquidity and market liquidity risks $(s c g)^{10}$.

\section{Credit Risk, Liquidity, Systematic Liquidity Risk and Correlation premia: Cross-sectional Results}

\subsection{Factor Sensitivities}

In this subsection we present the results related to the factor sensitivity matrix and discuss the interactions between credit, liquidity and systematic liquidity risks.

\subsubsection{Rating BBB, BB and CCC}

Table 3 shows that pure default risk $x$ has a positive impact on bond and global bond liquidity risk $\left(f_{b}, f_{g b}\right)$. The positive sign suggests that high credit risk increases liquidity risk of the bond and the

\footnotetext{
${ }^{10} \mathrm{~A}$ more rigorous definition on how to measure credit and liquidity risks is available in Appendix B of Buhler and Trapp (2010)
} 
sovereign bond market, this is consistent with the idea that higher credit risk makes investors more risk averse and therefore bond liquidity drops. Secondly, it seems that pure default risk $x$ influences positively CDS bid liquidity and global CDS bid liquidity risk $\left(f_{b i d}, f_{g c b i d}\right)$ implying that high default risk leads to high CDS bid liquidity risk which suggests that dealers are less willing to buy protection from investors, the result is intuitive as high credit risk increases CDS premia and dealers might find it more attractive to sell protections than buy them.

On the other hand, the table shows that the magnitude of $g$ (i.e liquidity risk impact on the credit risk premia $\lambda$ ) is higher than $f^{11}$. In total, the four parameters $\left(g_{a s k}, g_{\text {bid }}, g_{\text {gcask }}, g_{\text {gcbid }}\right)$ which represent the impact of CDS liquidity and CDS global liquidity risk on credit risk carry negative signs (Table 2 and 3), this result suggests that high liquidity risk increases the credit risk premia $\lambda$, this is in line with our intuition as in case of high liquidity risk, CDS dealers demand more compensation on the ask side of the trade and require a discount on the bid side, which lead to high bid-ask spreads. Moreover, the impact of CDS bid liquidity risk is higher than that of the ask which infers that when CDS bid liquidity risk is high i.e when CDS dealers are less willing to buy protection from investors, CDS spreads tend to widen more.

The impact of bond liquidity and bond market liquidity show positive and negative sign respectively. The positive sign of $g_{b}$ implies that high bond liquidity risk increases the credit risk premia, this can be explained by the fact that high bond liquidity risk makes the delivery option illiquid and dealers require additional compensation for that which results in high bid-ask spread. The parameter $g_{g b}$ shows a negative sign which means that high bond market liquidity risk leads to low credit risk premia. In fact if, because of liquidity issues, investors have trouble taking long (short) credit risk positions in the bond market, they use the CDS market as substitute which lowers CDS liquidity risk and thus the spreads.

The 8 parameters $\left(w_{b, a s k}, w_{b, b i d}, w_{b, g c a s k}, w_{b, g c b i d}, w_{g b, a s k}, w_{g b, b i d}, w_{g b, g c a s k}\right.$ and $\left.w_{g b, g c b i d}\right)$ that reflect the impact of bond liquidity on CDS liquidity have negative signs implying that high liquidity risk in the bond market decreases CDS liquidity risk, this is consistent with the sign of $g_{g b}, w_{b, g b}$. However the opposite is not true as high CDS liquidity risk leads to high bond liquidity risk, this finding is interesting in itself because it shows that when the CDS market is illiquid it ultimately impacts bond liquidity, this is possible in a situation where market participants invest in the sovereign bond market and hedge their position with CDSs in the same time. This support the idea that bond and CDS markets not only complete each other but also act as a substitute.

Finally, the parameters ( $w_{\text {gcask }, a s k}, w_{\text {gcbid,ask }}, w_{\text {bid,gcask }}, w_{\text {bid,gcbid }}$ and $w_{\text {gcask,gcbid }}$ ) reflecting the interaction between CDS liquidity and CDS market liquidity risk have negative signs ${ }^{12}$ which indicates

\footnotetext{
${ }^{11} f$ represents the impact of the pure default risk $x$ on liquidity risk $\gamma$.

${ }^{12}$ All the parameters display negative sign besides $w_{b i d, g c b i d}$.
} 
that CDS market liquidity risk increases CDS liquidity risk, this finding supports our model and implies that CDS market liquidity does carry an extra premium because if the whole market is illiquid then this could worsen the liquidity of individual CDSs.

Rating BB, and $\mathrm{CCC}$ suggests the same implications as Rating BBB and the difference lies in the magnitude of the coefficients. However, rating A shows different results and therefore deserves a separate discussion.

\subsubsection{Rating A}

Table 3 shows that pure default risk $x$ has a positive impact on bond liquidity $f_{b}$ and global bond liquidity $f_{g b}$ however $x$ does not affect CDS liquidity and CDS market liquidity as the factors $f_{\text {ask }}=$ $f_{\text {bid }}=f_{\text {gcask }}=f_{\text {gcbid }}=0$. Furthermore, the sign of $g_{\text {ask }}$ and $g_{\text {bid }}$ implies that CDS liquidity has a positive impact on credit risk premia $\lambda$. However, CDS market liquidity $\left(g_{\text {gcask }}, g_{\text {gcbid }}\right)$ shows negative sign, this result is in sharp contrast with previous ratings and indicates that high market liquidity risk decreases credit risk premium $\lambda$. This suggests that if there is high liquidity risk in the CDS market and therefore high spreads in Rating BBB, BB and CCC, investors prefer to trade safer and cheaper securities (i.e rating A) which results in lower liquidity risk and thus lower spreads. This is consistent with what we observe in Figure 2 as liquidity risk in rating A is relatively low compared to the other ratings.

Bond liquidity $g_{b}$ affects negatively $\lambda$ this is also opposite to our previous results and shows that high bond liquidity risk reduces the spreads. This implies that the delivery option impact CDS spreads for rating $\mathrm{A}$ in a different manner, this might be possible if market participants do not ask for extra compensation for illiquid bonds because the probability of default is quite low. However, what the negative sign might suggest is that when bond liquidity is low, investors use the CDS market to take an equivalent position which results in lower liquidity risk and thus lower CDS spreads. Furthermore, $g_{g b}$ increases $\lambda$ which infers that high bond market liquidity risk increases the credit risk premia, this is consistent with the hedging effect.

$w$ captures the liquidity spill-over and displays effects similar to the previous ratings. The majority of the parameters have negative signs implying that high CDS liquidity risk triggers high liquidity risk in the bond market. Finally, the parameters reflecting the interaction between CDS liquidity and CDS market liquidity risk are all equal to 0 (or very close to zero) suggesting that the influence of CDS market liquidity on CDS liquidity of A-rated countries is very weak. 


\subsubsection{Summary}

Overall the results suggest that liquidity and market liquidity risk impact strongly the credit risk premia $\lambda$ and pure default risk $x$ has a lesser effect on CDS liquidity ${ }^{13}$. On the other hand, our tables show that high default risk increases bond liquidity risk and it also appears that liquidity risk has an inflating effect (i.e increases CDS spreads) as the intuition suggests. Furthermore, our estimations reveal that CDS and bond markets both substitute and complete each other, in case of high CDS liquidity risk, the bond market becomes illiquid and in case of high bond liquidity risk the CDS market becomes more liquid. Finally, our results indicate that CDS liquidity and CDS market liquidity are positively correlated. If CDS market liquidity is low it negatively influences the instrument-specific liquidity even though the asset is liquid. This finding supports the idea that market liquidity carry an extra premium on a top of the instrument-specific liquidity and that CDS market liquidity participates directly to CDS spread movements.

\subsection{Premia components}

In this subsection, we do a comparative analysis across ratings and discuss the implications for our results. Table 4 presents the model implied premia components of each rating for bonds and CDSs. The model shows that the difference in value of the bond pure credit risk premium $b d$ across ratings is small. The weight of $b d$ tends to increase as the rating decreases, however, its value drops for rating $\mathrm{CCC}$. The bond pure liquidity premium $b l$ decreases in percent term as the rating decreases. Table 4 indicates that rating CCC has the lowest value $b l$, this means that investors give more importance to bonds with lower ratings. On the other hand rating $\mathrm{CCC}$ has the highest $b l g$, this demonstrates that rating $\mathrm{CCC}$ is the most sensitive to market liquidity risk and thus carries the highest premia.

The overall magnitude of the correlation premia $s c$, representing the interaction between credit risk premia and liquidity risk, is quite small and shows a positive sign, this is consistent with our previous findings on the factor sensitivities as it shows that credit risk premia and liquidity risk are positively correlated, this result is also in line with Beber et al (2009) and Favero et al (2010). Finally, the extra correlation premia $s c g$, corresponding to the interaction between credit risk premia and systematic liquidity risk, also has a positive sign indicating that bond market liquidity risk and credit risk are positively related.

On average, for rating A we find that $b d$ represents $94 \%$ of the sovereign bond spread, $b l 2.8 \%$, blg $0.72 \%$, bc $1.75 \%$ and $b c g$ 0.07\%. For rating $\mathrm{BBB}, b d$ represents $97 \%$ of the sovereign bond

\footnotetext{
13 The results reported by BT on corporate CDS spreads show that $x$ influences liquidity but liquidity risk has no impact on $\lambda$
} 
spreads, $b l 1.11 \%$, blg $0.5 \%, b c 0.9 \%$ and $b c g$ 0.23\%. For rating BB $b d$ represents $99.75 \%$ of the sovereign bond spreads, $b l 0.11 \%$, blg $0.11 \%$, bc $0.0045 \%$ and $b c g 0.016 \%$. Finally, for rating CCC $b d$ represents $97.57 \%$ of the sovereign bond spreads, $b l 0.13 \%$, blg $1.5 \%, b c 0.59 \%$ and $b c g 0.16 \%$.

These finding indicate that the pure default risk represents the majority of the bond spreads and that liquidity risk plays a minor role. This result is in a sharp contrast with the corporate bond literature, where $60 \%$ of bond spreads is attributed to default risk but is largely supported by the sovereign literature. Geyer et al (2004) and Codogno et al (2003) find that the yield differentials under the EMU are mainly explained by a common default risk factor measured by the difference between corporate and government bond yields and that liquidity effects have a trivial role. Using a sample period from 2003 to 2004 Beber et al (2009) study the default versus liquidity decomposition in the sovereign bond market and find that credit represents $89 \%$ of sovereign bond spreads while liquidity account for $11 \%$. Favero et al (2010) show that the aggregate risk proxied by the difference between US corporate and government bonds is the most important explanatory variable for Euro-area differentials and that liquidity effect is present for only few countries. Finally, Monfort and Renne (2011) show that the liquidity part of the spreads is less important than the credit related one even though liquidity plays a non trivial role ${ }^{14}$.

On the other hand, the results from the CDS decomposition show that the CDS pure credit risk premium $s d g$ represents only $50 \%$ of the spreads and is stable across all the ratings. The CDS pure liquidity premium $s l$ accounts for a substantial part of the CDS spreads across the ratings. The negative sign of $s l$ combined with the negative factor sensitivity suggests that CDS liquidity has an increasing effect and this in line with our previous findings. Similarly to the sovereign bond market, $s l$ has the highest percent for rating A. The CDS pure global liquidity premium slg also shows negative signs for all the ratings implying a positive relationship between CDS spreads and CDS market liquidity. Furthermore, it appears that $s l g$ carries the highest weights for the lowest ratings BB and CCC, this is partly consistent with our results on the sovereign bonds. Although CDS pure correlation premium $s c$ and $s c g$ are tiny, they are positive for all the ratings and this further supports the idea that credit and liquidity risks co-move in the same direction.

On average, for rating A $s d g$ corresponds to $49.87 \%$ of the CDS spreads, $s l$ to $49.59 \%$, slg to $0.2 \%, s c$ to $0.064 \%$ and $s c g$ to $0.25 \%$. For rating BBB $s d g$ corresponds to $50 \%$ of the CDS spreads, $s l$ to $49.3 \%$, slg to $0.63 \%$, sc to $0.017 \%$ and $s c g$ to $0.039 \%$. For rating BB $s d g$ corresponds to $50 \%$ of the

\footnotetext{
${ }^{14}$ Although our results on bond spreads are in line with the majority of sovereign literature they are not consistent with Schwarz (2010). In her approach, the author regresses the bond yield differentials against credit risk and liquidity risk proxies and explains that market liquidity account for $68 \%$ of sovereign bond spreads, this is surprisingly high. In fact, using sovereign CDS differentials as a credit risk proxy in the regression is a questionable method because it might reduce the credit risk explanatory power and this may explain why liquidity represents significant portion of the bond yields.
} 
CDS spreads, $s l$ to $47.8 \%$, slg to $2.1 \%$, sc to $0.018 \%$ and $s c g$ to $0.055 \%$. Finally, for rating CCC sdg corresponds to $50 \%$ of the CDS spreads, sl to $48.57 \%$, slg to $1.5 \%$, sc to $0.004 \%$ and scg to $0.0029 \%$.

The weight of the pure credit risk in the sovereign CDS spreads seem to be small comparing to the corporate CDSs where BT(2010) and Lin et al (2009) find a percentage of 95\% and 87\% respectively. In fact, the literature that decomposes sovereign CDS spreads is tiny and to the best of our knowledge only three papers tried to do this task (Pan and Singleton (2008), Remonola et al (2008) and Longstaff et al (2010). Remonala et al (2008) provide the first study in this direction and show that the jumpat-default risk is priced in the sovereign CDS spreads. Longstaff et al (2010) extend the model of Pan and Singleton (2008) in order to decompose sovereign CDS spreads and calculate the risk premium related to distress risk. By applying the model to a large set of countries, they found that on average $34 \%$ of the spreads are due to risk premium. If we only take the average risk premium of the countries that both papers have in common ${ }^{15}$, we obtain a value of $41 \%$. The magnitude of the liquidity risk premium we find across all the ratings (i.e 48.79\%) is in line with their study. Finally, our results show that, on one hand, flight-to-liquidity risk has an impact on the credit risk premia $\lambda$ through $g_{g b}$ and on the CDS bid-ask spreads through $w_{g b, b i d}$ and $w_{g b, a s k}$. On the other hand systematic liquidity risk also influences CDS bid-ask spreads through $w_{\text {ask,gcask }}$ and $w_{\text {bid,gcbid }}$. However, the combined effect is small across all the ratings.

In summary, our estimation reveals that sovereign CDS spreads are highly impacted by liquidity risk and that sovereign bond spreads are less subject to liquidity frictions which implies that bond spreads represent a better poxy for sovereign default risk. Secondly, although bond and CDS markets are exposed to global liquidity risk, none of these spreads seem to be heavily impacted by the systematic liquidity and flight-to-liquidity risks. Finally, the weight of the correlation premia is negligible relatively to the other risk factors.

\section{Dynamic Interactions between CDS and Bond Markets: Long Run Relationship}

In this section we study the dynamic interactions between CDS and bond markets. We focus on the long run relationship between bond and CDS premia for the subinvestment and investment grades ${ }^{16}$.

The analysis is based on an econometric model that requires cointegration test between $b d$ and $s d g$, bla and sla and $b c a$ and $s c a$ where bla is the average of $b l$ and $b l g$, sla the average of $s l$ and $s l g$, $b c a$ the average of $b c$ and $b c g$ and $s c a$ the average of $s c$ and $s c g$.

\footnotetext{
${ }^{15}$ The countries that Longstaff et al (2011) and this paper have in common are Brazil, Chile, Colombia, Korea, Mexico, Philippines, South Africa and Turkey, thus Longstaff et al (2011) cover $80 \%$ our sample.

${ }^{16}$ Subinvestment grade represents the average of rating BBB, BB and CCC. Investment grade corresponds to rating A.
} 
If the series are non-stationary ${ }^{17}$ and cointegrated, we estimate the Johansen Vector Error Correction Model (VECM) in order to study the long run relationship between premia and the short term deviations (i.e adjustment speed). The VECM approach is very sensitive to the number of lags included in the estimation therefore in order to define the optimal lag number we use the Akaike Information Criterion (AIC) and pick the number of lags with the smallest AIC. In Table 5 we present the maximum likelihood estimation of the cointegrated vector (i.e unnormalised vector) and the vector of adjustment parameters ${ }^{18}$.

On the other hand, if the series are not cointegrated we apply the Granger-Causality test in order to find which market leads the other in terms of price discovery. In fact, this test has limits because if we find a two way relationship then we can not infer which market plays the leading role in term of price discovery. Since our dataset covers the crisis period, we split the sample into two in order to be able to interpret the dynamics under different market conditions.

\subsection{Pre-crisis}

Panel A and B of Table 5 report the results of our estimation for the subinvestment grade category. We document that for the pre-crisis period $s d g$ granger-cause $b d$ at $1 \%$ significance level which implies that the lagged values of pure credit risk premia $s d g$ give strong information on the future values of $b d$. On the other hand, liquidity premia seems to be neither cointegrated nor granger-caused indicating that $b l a$ and sla are independent from each other during pre-crisis time. The correlation premia of the bond and the CDS markets are cointegrated with positive sign implying a negative relationship between the premia. This finding indicates that when default risk and liquidity risk are positively correlated in the bond market, the opposite applies to the CDS market (i.e negative correlation between default risk and CDS liquidity risk). This scenario is likely if an increase in default probability increases bond liquidity risk which induce investors to use CDSs as an alternative, this is consistent with what we discussed before.

The investment grade group displays different findings. In fact, there is no cointegration or granger causality between the credit risk premia in both markets. However the lagged values of liquidity premia of the CDS market provide information on the future values of bond liquidity. Moreover, the correlation premia shows a positive and strong cointegration similar to the subinvestment grade.

\footnotetext{
${ }^{17}$ We apply the Augmented Dickey-Fuller (ADF) to test for the unit root effect.

18 Our interpretation of the cointegration relationship will be based on the normalised cointegration vector with respect to the first variable.
} 


\subsection{Post-crisis}

Panerl C and B show the results for the crisis period. Panel $\mathrm{C}$ reveals that the granger causality relation between $s d g$ and $b d$ is not valid anymore which indicate that CDS spreads do not play the leading role in the price discovery, this might be due to the fact that bond liquidity is more pressurizing on $s d g$ drifting it away from $b d$. Furthermore, liquidity premium are cointegrated with a positive sign indicating that there is a negative relationship between bond and CDS liquidity. If there is a flight-toliquidity in the sovereign bond market and investors use CDSs to trade credit risk then our results are consistent with the idea that high bond liquidity risk decreases CDS liquidity risk, in line with what we reported previously. The results also reveal that the adjustment speed to the long run relationship is stronger for bond than for CDS spreads. Finally, the correlation premium are cointegrated just like the pre crisis period however the sign of the cointegration is negative implying a positive relationship between correlation premia. The positive sign is consistent with the hedging effect during crisis period.

The credit risk premium in investment grade category show no evidence of cointegration or granger causality which is similar to the investment grade category. On the other hand, liquidity premia in both markets equally granger cause each other which infers that none of two markets lead the price discovery. Similarly to previous results, the correlation premium show strong cointegration.

In summary, Table 5 indicates that liquidity premia across the bond and the CDS markets are more related during crisis time and this is in line with the findings of Giovanni et al (2011) who document a strong commonality in liquidity between sovereign CDS and bond markets during the period (20072010). On the other hand, the credit risk premium across both markets are not strongly related this indicate that bond liquidity plays an important role in CDS spread movements and this consistent with our previous results showing that liquidity risk represents a significant part of CDS spreads. Overall, the correlation premium for both markets are cointegrated across all the ratings and periods implying that there is a stable and long run relationship between $b c a$ and $s c a$.

\section{Conclusion:}

In this paper, we provide the first study that quantifies the size of the credit risk, liquidity and correlation components in sovereign CDS spreads. In order to carry out this analysis, we extend the factor model of Buhler and Trapp (2010) and jointly calibrate it to both CDS and bond data. By doing so, we are able to use a large amount of information on sovereign default risk and thus present a better decomposition of sovereign bond and CDS spreads. Our results reveal that default risk represents on average $97.08 \%$ of the bond spreads, liquidity risk $1.73 \%$ and correlation risk $0.93 \%$. On the CDS side we find that, on average, default risk account for $50 \%$ of the spreads, liquidity risk for $49.91 \%$ and correlation risk for $0.09 \%$. 
Overall, our results reveal that sovereign CDS spreads are highly impacted by liquidity risk and that sovereign bond spreads are less subject to liquidity frictions and therefore represent a better proxy for sovereign default risk. Secondly, although sovereign bond and CDS markets are subject to global liquidity shocks, none of them seem to be heavily impacted by systematic liquidity and flight-toliquidity risks.

Our results find large support in the literature. Codogno, Favero and Missale (2003), Geyer, Kossmeier and Pichler (2004), Beber, Brandt and Kavajecz (2009), Favero, Pagano and Thadden (2010) and Monfort and Renne (2011) provide the evidence that default risk represents the majority of bond spreads and that liquidity risk plays a minor role. On the other hand, Longstaff et al (2011) document that $41 \%$ of sovereign CDS spreads are due to distress risk premium, we report that $48.79 \%$ of CDS spreads are due to liquidity risk premium.

Our paper has important implications for practitioners and policy makers and enhances our understanding of the main drivers of sovereign bond and most importantly sovereign CDS spreads because if high CDS spreads implies high liquidity risk instead of high default risk then central banks could take appropriate measures to monitor liquidity risk embedded in the CDS spreads. Furthermore our findings give clear indication that liquidity is a dangerous risk that could influence assets by drifting them away from their fundamental values. Therefore policy makers should enable the trading of CDSs only to those who hold the underlying asset. Further research should be done to better understand the effects of banning CDS speculative trading. 


\section{References}

V.V. Acharya and L.H. Pedersen. Asset pricing with liquidity risk. Journal of Financial Economics, 77(2):375-410, 2005. ISSN 0304-405X.

J. Ammer and F. Cai. Sovereign CDS and bond pricing dynamics in emerging markets: does the cheapest-to-deliver option matter? FRB International Finance Discussion Paper No. 912., 2007.

P. Augustin and R. Tedongap. Commonality in Sovereign CDS Spreads: A Consumption-Based Explanation. Working paper, 2010.

A. Beber, M.W. Brandt, and K.A. Kavajecz. Flight-to-quality or flight-to-liquidity? Evidence from the Euro-area bond market. Review of Financial Studies, 2008. ISSN 0893-9454.

A. Berndt, R. Douglas, D. Duffie, M. Ferguson, and D. Schranz. Measuring default risk premia from default swap rates and EDFs.

D. Brigo, M. Predescu, and A. Capponi. Credit default swaps liquidity modeling: A survey. Working paper, 2010.

M.K. Brunnermeier and L.H. Pedersen. Market liquidity and funding liquidity. Review of Financial Studies, 2008. ISSN 0893-9454.

Buhler and Trapp. Time-varying credit risk and liquidity premia in bond and cds markets. 2010.

G. Calice, J. Chen, and J. Williams. Liquidity interactions in credit markets: An analysis of the eurozone sovereign debt crisis. Journal of Economic Behavior and Organization, 2011.

L. Codogno, C. Favero, and A. Missale. Yield spreads on emu government bonds. Economic Policy, 18(37):503-532, 2003.

J. Driessen. Is default event risk priced in corporate bonds? Review of Financial Studies, 18(1): 165-195, 2005.

K. Dunbar. Us corporate default swap valuation: the market liquidity hypothesis and autonomous credit risk. Quantitative Finance, 8(3):321-334, 2008.

C. Favero, M. Pagano, and E.L. Von Thadden. How does liquidity affect government bond yields? Journal of Financial and Quantitative Analysis, 45(01):107-134, 2010.

A. Fontana and M. Scheicher. An analysis of euro area sovereign CDS and their relation with government bonds. ECB Working Paper No. 1271, 2010.

A. Geyer, S. Kossmeier, and S. Pichler. Measuring systematic risk in emu government yield spreads. Review of Finance, 8(2):171-197, 2004.

J. Gonzalo and C. Granger. Estimation of common long-memory components in cointegrated systems. Journal of Business \& Economic Statistics, pages 27-35, 1995. 
S. Han and H. Zhou. Nondefault bond spread and market trading liquidity. Federal Reserve Board, 2006.

J. Huang and M. Huang. How much of the corporate-treasury yield spread is due to credit risk? NYU Working Paper No. S-CDM-02-05, 2002.

I. Ismailescu and B. Phillips. Savior or sinner? credit default swaps and the market for sovereign debt.

H. Lin, S. Liu, and C. Wu. Liquidity premia in the credit default swap and corporate bond markets. 2009.

S. Liu, J. Shi, J. Wang, and C. Wu. How much of the corporate bond spread is due to personal taxes? Journal of Financial Economics, 85(3):599-636, 2007.

F.A. Longstaff and E.S. Schwartz. A simple approach to valuing risky fixed and floating rate debt. Journal of finance, pages 789-819, 1995.

F.A. Longstaff, S. Mithal, and E. Neis. Corporate yield spreads: Default risk or liquidity? new evidence from the credit default swap market. The Journal of Finance, 60(5):2213-2253, 2005.

F.A. Longstaff, J. Pan, L.H. Pedersen, and K.J. Singleton. How sovereign is sovereign credit risk? American Economic Journal, 2011.

L. Meng and O. Gwilym. The determinants of cds bid-ask spreads. The Journal of Derivatives, 16(1): 70-80, 2008.

A. Monfort and J.P. Renne. Credit and liquidity risks in euro-area sovereign yield curves. Working Paper, 2011.

A. Nashikkar and M. Subrahmanyam. Latent liquidity and corporate bond yield spreads. NYU Working Paper No. FIN-06-023, 2006.

J. Pan and K.J. Singleton. Default and recovery implicit in the term structure of sovereign CDS spreads. The Journal of Finance, 63(5):2345-2384, 2008. ISSN 1540-6261.

S. Panyanukul. Liquidity Risk and the Pricing of Sovereign Bonds in Emerging Markets. Working paper, 2010.

X. Pu. Liquidity commonality across the bond and cds markets. The Journal of Fixed Income, 19(1): 26-39, 2009.

J. Qiu and F. Yu. Endogenous liquidity in credit derivatives. Working Paper, 2010.

E.M. Remolona, M. Scatigna, and E. Wu. The Dynamic Pricing of Sovereign Risk in Emerging Markets. The Journal of Fixed Income, 17(4):57-71, 2008. ISSN 1059-8596.

D.Y. Tang and H. Yan. Liquidity and credit default swap spreads. Working paper, 2009.

D.Y. Tang and H. Yan. Does the tail wag the dog? the price impact of cds trading. Working Paper, 2010. 
H. Zhu. An empirical comparison of credit spreads between the bond market and the credit default swap market. Journal of Financial Services Research, 29(3):211-235, 2006. 


\section{Appendix: Analytical Solutions for the Discount factors}

In this appendix, we present in some details the derivations of the discount factors of equation (7), (8) and (9). The derivations are similar for the discount factor of the CDS bid, CDS ask and bonds, thus we only present the solutions of the bonds.

\section{A. Solving the Expectations in the CDS and Bond using the PDE approach (simultaneous dis-} count factor): $D\left(t, T_{i}\right) * E_{t}\left[P\left(t, t_{i}\right) * L^{b}\left(t, t_{i}\right) * L^{g b}\left(t, t_{i}\right)\right]$

Let's denote $x(t)=\lambda^{i}(t), \lambda^{i}$ corresponds to the pure default intensity.

$$
\begin{aligned}
E_{t}\left[P\left(t, t_{i}\right) * L^{b}\left(t, t_{i}\right) * L^{g b}\left(t, t_{i}\right)\right] & =E_{t}\left[\exp \left(-\int_{0}^{\tau} \lambda_{s}+\gamma_{s}^{b}+\gamma_{s}^{g b} d s\right)\right] \\
=E_{t}\left[\exp \left(-\int_{0}^{\tau}\left(1+f_{b}+f_{g b}\right) * \lambda \lambda^{i} d s\right]\right. & * E_{t}\left[\exp \left(-\int_{0}^{\tau}\left(1+g_{b}+w_{g b, b}\right) * y^{b} d s\right)\right] \\
E_{t}\left[\exp \left(-\int_{0}^{\tau}\left(g_{a s k}+w_{b, a s k}+w_{g b, a s k}\right) * y^{a s k} d s\right)\right] & * E_{t}\left[\exp \left(-\int_{0}^{\tau}\left(g_{b i d}+w_{b, b i d}+w_{g b, b i d}\right) * y^{b i d} d s\right)\right] \\
E_{t}\left[\exp \left(-\int_{0}^{\tau}\left(w_{b, g c a s k}+g_{\text {gcask }}+w_{\text {gb gcask }}\right) * y^{g c a s k} d s\right)\right] * & \\
E_{t}^{\tau}\left[\exp \left(-\int_{0}^{\tau}\left(w_{b, g c b i d}+g_{g c b i d}+w_{g b, g c b i d}\right) * y^{g c b i d} d s\right)\right] &
\end{aligned}
$$

This decomposition allows us to retrieve the independent intensities which in turn enables us to solve each expectation separately. We first solve for $P(\lambda, T)=E_{t}\left[\exp \left(-\int_{0}^{\tau}\left(1+f_{b}+f_{g b}\right) * \lambda^{i}\right]\right.$ and apply Ito Lemma to get the PDE:

$$
-\left(1+f_{b}+f_{g b}\right) * \lambda_{t}^{i} * P(\lambda, t)-P_{T}+P_{\lambda}\left(\alpha-\beta * \lambda^{i}\right)+\frac{1}{2} * P_{\lambda \lambda} * \sigma^{2} * \lambda^{i 2}=0
$$

We guess a solution for the $P(\lambda, T)$

$$
P(\lambda, T)=a_{1}(T) * \exp \left(-a_{2}(T) * \lambda^{i} *\left(1+f_{b}+f_{g b}\right)\right)
$$


We solve for $a_{1}(T)$ and $a_{2}(T)$ by solving the following system of ODEs:

$$
\left\{\begin{array}{c}
-1-a_{2}^{\prime}-\beta * a_{2}+\frac{\sigma^{2}}{2} *\left(1+f_{b}+f_{g b}\right) * a_{2}^{2}=0 \\
-a_{1}^{\prime}+\alpha * a_{1} *\left(1+f_{b}+f_{g b}\right) * a_{2}=0
\end{array}\right.
$$

We retrieve the following solutions:

$$
\begin{gathered}
a_{1}(T)=\left(\frac{1-\kappa}{1-\kappa * \exp (\phi(\tau-t))}\right)^{\frac{2 \alpha}{\sigma^{2}}} * \exp \left(\frac{\alpha(\beta+\phi)}{\sigma^{2}} *(\tau-t)\right) \\
a_{2}(T)=\frac{\phi-\beta}{\sigma^{2} *\left(1+f_{b}+f_{g b}\right)}+\frac{2 * \phi}{\sigma^{2} *\left(1+f_{b}+f_{g b}\right) *(\kappa * \exp (\phi(\tau-t))-1)}
\end{gathered}
$$

where

$$
\phi=\sqrt{2 * \sigma^{2} *\left(1+f_{b}+f_{g b}\right)+\beta^{2}}
$$

and

$$
\kappa=\frac{\beta+\phi}{\beta-\phi}
$$

We solve liquidity discount factors in the same manner, we have in total 6 liquidity intensities:

$$
F(\gamma, T)=E_{t}\left[\exp \left(-\int_{0}^{\tau} K * y d s\right)\right]
$$

where "K" changes with the liquidity intensity: 


$$
\left\{\begin{array}{c}
K=\left(1+g_{b}+w_{g b, b}\right) \\
K=\left(g_{\text {ask }}+w_{b, a s k}+w_{g b, a s k}\right) \\
\text { or } \quad\left(g_{\text {bid }}+w_{b, b i d}+w_{\text {gb,bid }}\right) \\
K=\left(w_{b, g b}+g_{g b}+1\right) \\
K=\left(w_{b, g c a s k}+g_{\text {gcask }}+w_{\text {gb gcask }}\right) \\
K=\left(w_{b, g c b i d}+g_{\text {gcbid }}+w_{\text {gb }, \text { gcbid }}\right)
\end{array}\right.
$$

We then derive the PDE and guess a solution for $F(\gamma, T)$

$$
\begin{gathered}
-\gamma_{t} * K * F(\gamma, T)-F_{T}+\frac{1}{2} * F_{\gamma \gamma} * \eta_{t}^{2}=0 \\
F(\gamma, T)=a_{3}(T) * \exp \left(-a_{4}(T) * K * \gamma\right)
\end{gathered}
$$

Solving a system of ODEs:

$$
\left\{\begin{array}{c}
a_{4}^{\prime}(T)=-1 \\
-a_{3}^{\prime}(T)+\frac{1}{2} * \eta^{2} * T^{2} * K^{2} * a_{3}(T)=0
\end{array}\right.
$$

We retrieve:

$$
\begin{gathered}
a_{4}(\tau-t)=\tau-t \\
a_{3}(\tau-t)=\exp \left(\frac{K^{2} * \eta^{2} *(\tau-t)^{3}}{6}\right)
\end{gathered}
$$


B. Solving the Expectation in the CDS and Bond using the Moment Generating Function (MGF) (non-simultaneous discount factor):

$$
E_{t}\left[\triangle P\left(t, t_{i}\right) * L^{b}\left(t, t_{i}\right) * L^{g b}\left(t, t_{i}\right)\right]=E_{t}\left[\left(P\left(t, t_{j-1}\right)-P\left(t, t_{j}\right)\right) * L^{b}\left(t, t_{i}\right) * L^{g b}\left(t, t_{i}\right)\right]
$$

Assume $t=0, t_{j-1}=t_{1}$ and $t_{j}=t_{2}$ where $t<t_{j}<t_{j-1}$

$$
\begin{aligned}
& E_{t}\left[P\left(t, t_{1}\right) * L^{b}\left(t, t_{2}\right) * L^{g b}\left(t, t_{2}\right)\right]=E_{t}\left[\exp \left(-\int_{t}^{t_{1}} \lambda_{s} d s\right) * \exp \left(-\int_{t}^{t_{2}} \gamma_{s}^{b} d s\right) * \exp \left(-\int_{t}^{t_{2}} \gamma_{s}^{g b} d s\right)\right] \\
& =E_{t}\left[\exp \left(-\int_{t}^{t_{1}} \lambda_{s}\right) * \exp \left(-\int_{t}^{t_{1}} \gamma_{s}^{b} d s\right) * \exp \left(-\int_{t_{1}}^{t_{2}} \gamma_{s}^{b} d s\right) * \exp \left(-\int_{t}^{t_{1}} \gamma_{s}^{g b} d s\right) * \exp \left(-\int_{t_{1}}^{t_{2}} \gamma_{s}^{g b} d s\right)\right]
\end{aligned}
$$

Using the previous solutions of $P(\lambda, T)$, we transform the correlated intensities to non-correlated ones: 


$$
\begin{array}{r}
E_{t}\left[P\left(t, t_{1}\right) * L^{b}\left(t, t_{2}\right) * L^{g b}\left(t, t_{2}\right)\right]= \\
E_{t}\left[\exp \left(-\int_{t}^{t_{1}}\left(1+f_{b}+f_{g b}\right) * \lambda \lambda^{i} d s\right) * \exp \left(-\int_{t_{1}}^{t_{2}}\left(f_{b}+f_{g b}\right) * \lambda^{i} d s\right)\right] * \\
E_{t}\left[\exp \left(-\int_{t}^{t_{1}}\left(1+g_{b}+w_{g b, b}\right) * y^{b} d s\right) * \exp \left(-\int_{t_{1}}^{t_{2}}\left(1+w_{g b, b}\right) * y^{b} d s\right)\right] * \\
E_{t}\left[\exp \left(-\int_{t}^{t_{1}}\left(g_{\text {ask }}+w_{b, a s k}+w_{g b, a s k}\right) * y^{a s k} d s\right) * \exp \left(-\int_{t_{1}}^{t_{2}}\left(w_{b, a s k}+w_{g b, a s k}\right) * y^{a s k} d s\right)\right] * \\
\left.\left.\int_{t}^{t_{1}}\left(g_{b i d}+w_{b, b i d}+w_{g b, b i d}\right) * y^{b i d} d s\right) * \exp \left(-\int_{t_{1}}^{t_{2}}\left(w_{b, b i d}+w_{g b, b i d}\right) * y^{b i d} d s\right)\right] * \\
E_{t}\left[\exp \left(-\int_{t}^{t_{1}}\left(w_{g b, g c a s k}+w_{b, g c a s k}+g_{g c a s k}\right) * y^{g c a s k} d s\right) * \exp \left(-\int_{t_{1}}^{t_{1}}\left(w_{b, g c a s k}+w_{g b, g c a s k}\right) * y^{g c a s k} d s\right)\right] * \\
E_{t}\left[\exp \left(-\int_{t}^{t_{1}}\left(w_{b, g b c b i d}+g_{g c b i d}+w_{g b, g c b i d}\right) * y^{g c b i d} d s\right) * \exp \left(-\int_{t_{1}}^{t_{2}}\left(w_{b, g c b i d}+w_{g b, g c b i d}\right) * y^{g c b i d} d s\right)\right]
\end{array}
$$

$K_{1 i}=\left(w_{b, g c b i d}+g_{g c b i d}+w_{g b, g c b i d}\right)$ and $K_{2 i}=\left(w_{b, g c b i d}+w_{g b, g c b i d}\right)$ where $i=1,2, \ldots 6 . K_{1}$ and $K_{2}$ change with the liquidity intensity.

Using the law of iterated expectation we can solve the "second" exponential in each line by using $P(\lambda, T)$ and $F(\gamma, T)$ and transforming the equations into MGFs.

The final result for the default intensity is:

$$
\begin{gathered}
E_{t}\left[\exp \left(-\int_{t}^{t_{1}}\left(1+f_{b}+f_{g b}\right) * \lambda^{i} d s\right) * \exp \left(-\int_{t_{1}}^{t_{2}}\left(f_{b}+f_{g b}\right) * \lambda^{i} d s\right)\right]= \\
E_{t}\left[\exp \left(-\int_{t}^{t_{1}}\left(1+f_{b}+f_{g b}\right) * \lambda^{i} d s\right) * E_{t}\left[\exp \left(-\int_{t_{1}}^{t_{2}}\left(f_{b}+f_{g b}\right) * \lambda^{i} d s\right)\right]\right.
\end{gathered}
$$




$$
=-a_{1}\left(t_{1}, t_{2}\right) * E_{t}\left[\exp \left(-\int_{t}^{t_{1}}\left(1+f_{b}+f_{g b}\right) * \lambda^{i} d s\right) * \exp \left(-a_{2}\left(t_{1}, t_{2}\right) *\left(f_{b}+f_{g b}\right) * \lambda^{i}\left(t_{1}\right)\right)\right]
$$

where $a_{1}\left(t_{1}, t_{2}\right)$ and $a_{2}\left(t_{1}, t_{2}\right)$ are defined in Appendix A.

The final result for the liquidity process is:

$$
\begin{gathered}
E_{t}\left[\exp \left(-\int_{t}^{t_{1}} K_{1 i} * y d s\right) * \exp \left(-\int_{t_{1}}^{t_{2}} K_{2 i} * y d s\right)\right]=E_{t}\left[\exp \left(-\int_{t}^{t_{1}} K_{1 i} * y d s\right) * E_{t}\left[\exp \left(-\int_{t_{1}}^{t_{2}} K_{2 i} * y d s\right)\right]\right] \\
=a_{3}\left(t_{1}, t_{2}\right) * E_{t}\left[\exp \left(-\int_{t}^{t_{1}} K_{1 i} * y(t) d s\right) * \exp \left(-a_{4}\left(t_{1}, t_{2}\right) * K_{2 i} * y\left(t_{1}\right) d s\right)\right]
\end{gathered}
$$

where $a_{3}\left(t_{1}, t_{2}\right)$ and $a_{4}\left(t_{1}, t_{2}\right)$ are defined in Appendix A.

Equation (28) and (29) are MGFs that will be solved in order to retrieve the closed form solution of the expectations ${ }^{19}$.

Solving the MGF of the default intensity gives:

$P\left(t,\left(1+f_{b}+f_{g b}\right),\left(f_{b}+f_{g b}\right)\right)=-a_{1}\left(t_{1}, t_{2}\right) * E_{t}\left[\exp \left(-\int_{t}^{t_{1}}\left(1+f_{b}+f_{g b}\right) * \lambda_{s}^{i} d s\right) * \exp \left(-a_{2}\left(t_{1}, t_{2}\right) *\left(f_{b}+f_{g b}\right) * \lambda_{s}^{i}\left(t_{1}\right)\right)\right]$

The guessed solution is:

$$
P\left(t,\left(1+f_{b}+f_{g b}\right),\left(f_{b}+f_{g b}\right)\right)=a_{1}\left(t_{1}, t_{2}\right) * b_{1}\left(t, t_{1}, t_{2}\right) * \exp \left(-b_{2}\left(t_{1}, t_{2}\right) * \lambda^{i}\right)
$$

where:

$$
b_{1}\left(t, t_{1}, t_{2}\right)=\left(\frac{2 * \phi * \exp \left(\frac{\tau_{1-t}}{2}(\phi+\beta)\right)}{\sigma^{2} * a_{2}\left(t_{1}, t_{2}\right) *\left(f_{b}+f_{g b}\right) *\left(\exp \left(\phi\left(\tau_{1}-t\right)-1\right)+\phi-\beta+\exp \left(\phi\left(\tau_{1}-t\right)\right)(\phi+\beta)\right.}\right)^{\frac{2 * \alpha}{\sigma^{2}}}
$$

\footnotetext{
${ }^{19}$ The MGF will be solved using the Proposition 6.2.4 of Lamberton and Lapeyre (page 162), this proposition is used to characterize the joint law of $\left(X_{t}, \int_{0}^{t} X_{s} d s\right)$ (in our case $X_{t}$ is either equal to $\lambda_{s}^{i}$ or $\left.y^{l}\right)$ and is the key to any pricing within the CIR model. To solve the MGF of the liquidity intensities, we use the same law by assuming that a Gaussian process is a special case of a CIR process.
} 
$b_{2}\left(t, t_{1}, t_{2}\right)=\left(\frac{a_{2}\left(t_{1}, t_{2}\right) *\left(f_{b}+f_{g b}\right) *\left(\phi+\beta+\exp \left(\phi\left(\tau_{1}-t\right)\right)(\phi-\beta)+2 *\left(1+f_{b}+f_{g b}\right) *\left(\left(\exp \left(\phi\left(\tau_{1}-t\right)-1\right)\right.\right.\right.}{\sigma^{2} * a_{2}\left(t_{1}, t_{2}\right) *\left(f_{b}+f_{g b}\right) *\left(\exp \left(\phi\left(\tau_{1}-t\right)-1\right)+\phi-\beta+\exp \left(\phi\left(\tau_{1}-t\right)\right)(\phi+\beta)\right.}\right.$

Solving the MGF of the liquidity intensities leads to:

$$
L\left(t, K_{1}, K_{2}\right)=a_{3}\left(t_{1}, t_{2}\right) * E_{t}\left[\exp \left(-\int_{t}^{t_{1}} K_{1} * y d s\right) * \exp \left(-a_{4}\left(t_{1}, t_{2}\right) * K_{2} * y\left(t_{1}\right) d s\right)\right]
$$

We guess a solution

$$
L\left(t, K_{1}, K_{2}\right)=a_{3}\left(t_{1}, t_{2}\right) * b_{3}\left(t_{1}, t_{2}\right) * \exp \left(-b_{4}\left(t_{1}, t_{2}\right) * y\right)
$$

$$
b_{3}\left(t_{1}, t_{2}\right)=\exp \left[\frac{\eta^{2} * K_{1}^{2}}{6} *\left(\tau_{1}-1\right)^{3}+\frac{\eta^{2} * K_{2}^{2} * a_{4}\left(t_{1}, t_{2}\right)}{2} *\left(\tau_{1}-1\right)^{2}+\left(\frac{\eta^{2} * K_{2} * a_{4}\left(t_{1}, t_{2}\right)}{2}\right) * a_{4}\left(t_{1}, t_{2}\right) * K_{2} *\left(\tau_{1}-1\right)\right]
$$

and

$$
b_{4}\left(t_{1}, t_{2}\right)=a_{4}\left(t_{1}, t_{2}\right) * K_{2}+K_{1} *\left(\tau_{1}-1\right)
$$


Figure 1: Average Bond Spreads and CDS Mid Premiun for Ratings A, BBB, BB and CCC

The figures show the average bond spreads and CDS mid premia from November 2005 till September 2010 for rating $\mathrm{A}$ and $\mathrm{BBB}$ (top plot) and rating $\mathrm{BB}$ and $\mathrm{CCC}$ (bottom plot).
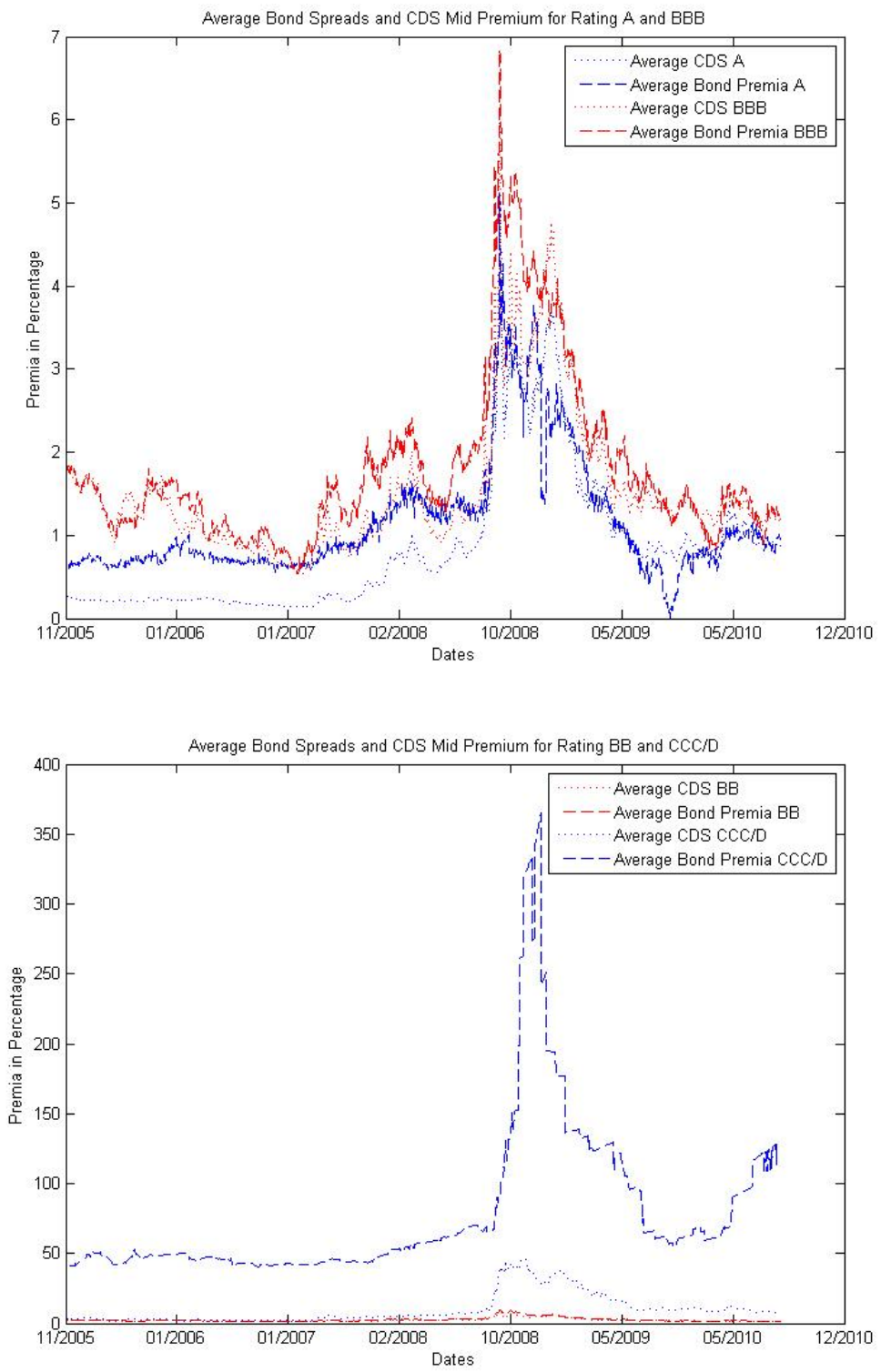
Figure 2: Pure intensities for Rating A, BBB/BB and CCC

This figure shows the pure intensities retrieved from the calibration procedure defined in Section 4 for rating A (three top plots), for the average rating BBB and BB (three middle plots) and for rating CCC (three bottom plots).
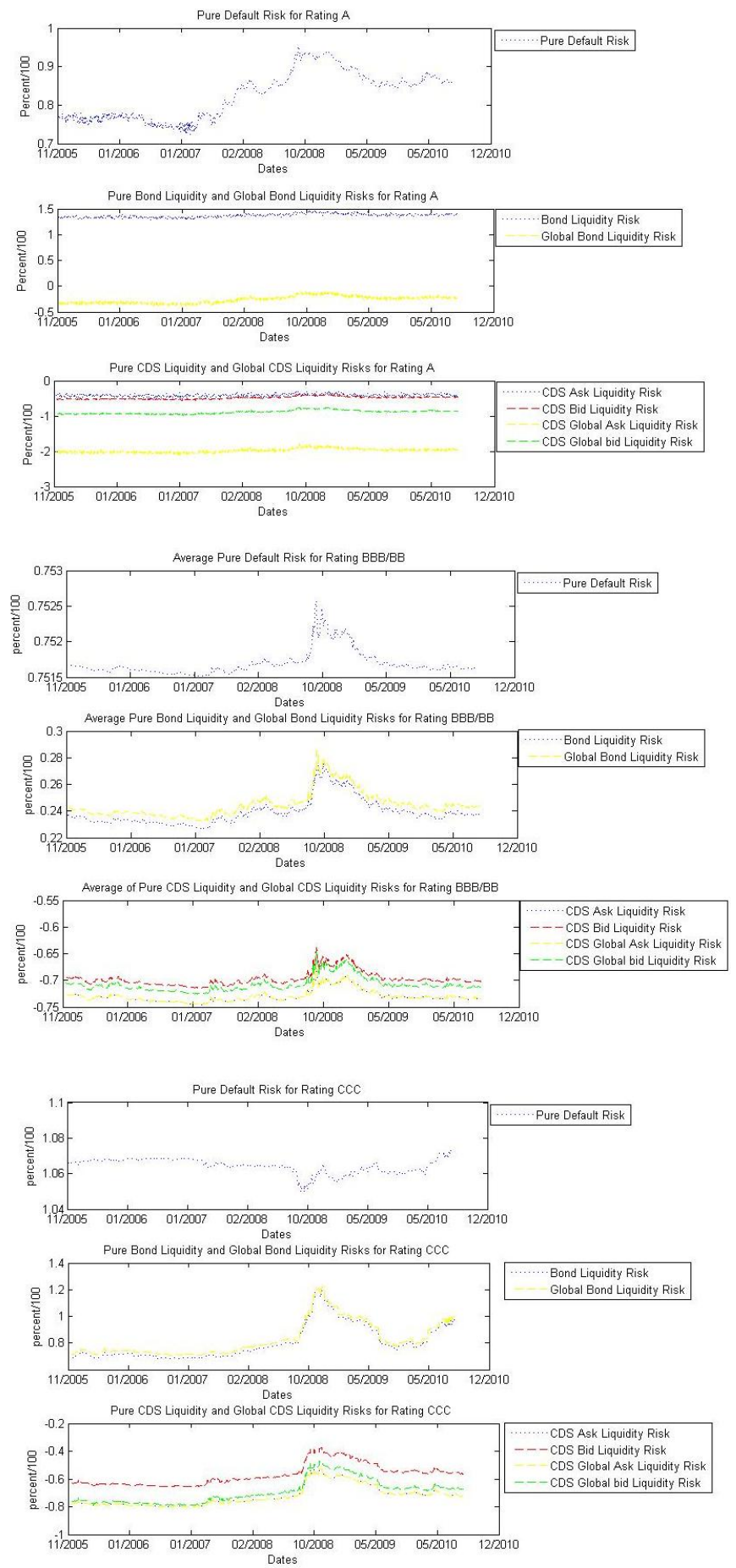


\section{Table 1: Latent Factors of Default and Liquidity Intensities}

In this table, we report the parameter values of the processes defining the default $x$ and liquidity intensities $y$. The values are retrieved at the end of the calibration procedure. $\eta$ and $\sigma$ are the volatility terms of the Gaussian and CIR processes. $\beta$ and $\alpha$ are the parameters specific to the drift of the CIR process.

\begin{tabular}{ccccc} 
& $\mathrm{A}$ & $\mathrm{BBB}$ & $\mathrm{BB}$ & $\mathrm{CCC}$ \\
\cline { 2 - 5 }$\eta_{b}$ & 0.001 & 0.107 & 0.02 & 0.104 \\
$\eta_{\text {ask }}$ & 0.271 & 0.01 & 0.081 & 0.071 \\
$\eta_{\text {bid }}$ & 0.48 & 0.106 & 0.082 & 0.126 \\
$\eta_{g b}$ & 0.01 & 0.01 & 0.02 & 0.0098 \\
$\eta_{\text {gcask }}$ & 0.175 & 0.01 & 0.08 & 0.0723 \\
$\eta_{\text {gcbid }}$ & 0.001 & 0.101 & 0.08 & 0.123 \\
$\sigma$ & 0.3 & 0.872 & 2 & 0.862 \\
$\beta$ & 0.115 & 0.208 & 0.3 & 0.207 \\
$\alpha$ & 0.28 & 1.03 & 0.1 & 1.038 \\
\hline
\end{tabular}




\section{Table 2: Independent Intensities}

The table reports the descriptive statistics of the pure intensities where $x$ corresponds to the pure default risk and $y_{b}$ pure bond liquidity, $y_{a s k}$ pure CDS ask liquidity, $y_{b i d}$ pure CDS bid liquidity, $y_{g b}$ pure global bond liquidity risk, $y_{\text {gcask }}$ pure global CDS ask liquidity and $y_{\text {gcbid }}$ pure global CDS bid liquidity risk.

\begin{tabular}{ccccccccc} 
& & $x$ & $y_{b}$ & $y_{\text {ask }}$ & $y_{\text {bid }}$ & $y_{g b}$ & $y_{\text {gcask }}$ & $y_{\text {gcbid }}$ \\
\cline { 3 - 9 } A & Mean & 0.825 & 1.36 & -0.41 & -0.48 & -0.26 & -1.98 & -0.88 \\
& Max & 0.95 & 5.53 & 4.7 & -0.37 & 4.57 & 3.83 & -0.19 \\
& Min & 0.723 & -3.82 & -6.36 & -0.89 & -4.11 & -6.76 & -1.17 \\
\hline \multirow{3}{*}{ BBB } & & & & & & & & \\
& Mean & 0.5102 & 0.35 & -0.85 & -0.79 & 0.36 & -0.85 & -0.81 \\
& Max & 0.5104 & 0.39 & -0.76 & -0.69 & 0.4 & -0.76 & -0.7 \\
& Min & 0.5108 & 0.343 & -0.887 & -0.82 & 0.355 & -0.88 & -0.85 \\
\hline \multirow{3}{*}{ BB } & & & & & & & & \\
& Mean & 0.9931 & 0.122 & -0.6 & -0.6 & 0.12 & -0.6 & -0.59 \\
& Max & 0.998 & 0.16 & -0.585 & -0.587 & 0.168 & -0.584 & -0.585 \\
& Min & 0.9927 & 0.108 & -0.604 & -0.603 & 0.108 & -0.603 & -0.602 \\
\hline \multirow{2}{*}{ CCC } & & & & & & & & \\
& Mean & 1.06 & 0.8 & -0.72 & -0.57 & 0.82 & -0.724 & -0.69 \\
& Max & 1.07 & 1.2 & -0.52 & -0.37 & 1.22 & -0.52 & -0.469 \\
& Min & 1.04 & 0.677 & -0.8 & -0.65 & 0.7 & -0.8 & -0.78 \\
\hline
\end{tabular}




\section{Table 3: Factor Sensitivities}

The table presents the values of factor sensitivities matrix of equation (4) which represents the interactions between default, liquidity and systematic liquidity risk. The matrix has been estimated using the calibration procedure defined in Section 4. $f$ corresponds to the impact of pure default risk $x$ on liquidity risk, $g$ the impact of liquidity risk on the credit risk premia $\lambda$ and $w$ represents the direct link between the different liquidity intensities.

\begin{tabular}{|c|c|c|c|c|}
\hline & $\mathrm{A}$ & BBB & BB & $\mathrm{CCC}$ \\
\hline$f_{b}$ & 0.038 & $1 e^{\wedge}-4$ & $2 e^{\wedge}-4$ & $1.2 \mathrm{e}^{\wedge}-4$ \\
\hline$f_{\text {ask }}$ & 0 & 0 & 0 & 0 \\
\hline$f_{\text {bid }}$ & 0 & $2 e^{\wedge}-4$ & $2 e^{\wedge}-4$ & $3 e^{\wedge}-4$ \\
\hline$g_{b}$ & -0.3324 & $5 e^{\wedge}-4$ & $2 e^{\wedge}-4$ & $6 e^{\wedge}-4$ \\
\hline$g_{\text {ask }}$ & -0.3282 & $-5 e^{\wedge}-4$ & $-2 e^{\wedge}-4$ & $-5 e^{\wedge}-4$ \\
\hline$g_{\text {bid }}$ & -0.0357 & -0.33 & $-2 e^{\wedge}-4$ & -0.34 \\
\hline$g_{g b}$ & -0.0031 & $-1.1 \mathrm{e}^{\wedge}-3$ & $-1 e^{\wedge}-4$ & -0.0011 \\
\hline$g_{\text {gcask }}$ & 0.0078 & $-6 e^{\wedge}-3$ & $-2 e^{\wedge}-3$ & $-5 e^{\wedge}-4$ \\
\hline$g_{\text {gcbid }}$ & 0.0075 & -0.033 & $-2 e^{\wedge}-3$ & -0.03 \\
\hline$w_{b, a s k}$ & 0.0305 & $-2 e^{\wedge}-4$ & $-2 e^{\wedge}-4$ & $-2 e^{\wedge}-4$ \\
\hline$w_{b i d, b}$ & -0.102 & -0.025 & $-2 e^{\wedge}-3$ & -0.026 \\
\hline$w_{g b, b}$ & 0.0422 & $-7 e^{\wedge}-4$ & $-2 e^{\wedge}-4$ & $-8 e^{\wedge}-4$ \\
\hline$f_{g b}$ & 0.0338 & $1 e^{\wedge}-4$ & $2 e^{\wedge}-4$ & 0 \\
\hline$f_{\text {gcask }}$ & 0 & 0 & 0 & 0 \\
\hline$f_{\text {gcbid }}$ & 0 & $2 e^{\wedge}-4$ & $2 e^{\wedge}-4$ & $3 e^{\wedge}-4$ \\
\hline$w_{b, g c a s k}$ & -0.0034 & $-6 e^{\wedge}-4$ & $-2 e^{\wedge}-4$ & $-5 e^{\wedge}-4$ \\
\hline$w_{b, g c b i d}$ & -0.032 & -0.032 & $-4 e^{\wedge}-4$ & -0.034 \\
\hline$w_{\text {bid,ask }}$ & $9 e^{\wedge}-4$ & -0.027 & $-2 e^{\wedge}-4$ & -0.028 \\
\hline$w_{a s k, g b}$ & 0.0305 & $-1.1 \mathrm{e}^{\wedge}-3$ & $-2 e^{\wedge}-4$ & -0.0013 \\
\hline$w_{\text {ask,gcask }}$ & 0 & $-7 e^{\wedge}-4$ & $-2 e^{\wedge}-4$ & $-6 e^{\wedge}-4$ \\
\hline$w_{\text {ask }, \text { cbid }}$ & 0 & -0.038 & $-2 e^{\wedge}-4$ & -0.039 \\
\hline$w_{g b, b i d}$ & -0.102 & -0.037 & $-2 e^{\wedge}-3$ & -0.0387 \\
\hline$w_{\text {bid,gcask }}$ & $9 e^{\wedge}-4$ & -0.027 & $-2 e^{\wedge}-4$ & -0.03 \\
\hline$w_{b i d, g c b i d}$ & 0 & $5 e^{\wedge}-4$ & $2 e^{\wedge}-4$ & $5 e^{\wedge}-4$ \\
\hline$w_{\text {gb,gcask }}$ & -0.0034 & $-1.3 \mathrm{e}^{\wedge}-3$ & $-2 e^{\wedge}-4$ & -0.0013 \\
\hline$w_{g b, g c b i d}$ & -0.0032 & -0.031 & $-2 e^{\wedge}-4$ & -0.032 \\
\hline$w_{\text {gcbid,gcask }}$ & 0 & -0.037 & $-2 e^{\wedge}-4$ & -0.039 \\
\hline
\end{tabular}




\section{Table 4: Pure Credit Risk, Liquidity, Global Liquidity Risk and Correlation Premia}

In this table, we report the results of our decomposition procedure defined in Section 5.2. In Panel A, we show the average and percentage value of Bond Pure Credit Risk Premium $(b d)$, Bond Pure Liquidity Premium $(b l)$, Bond Pure Global Liquidity Premium (blg), Bond Pure Correlation Premium $(b c)$ and Bond Pure Global Correlation Premium $(b c g)$. In Panel B, we show the average and percentage value of CDS Pure Credit Risk Premium $(s d g)$, CDS Pure Liquidity Premium ( $s l)$, CDS Pure Global Liquidity Premium (slg ), CDS Pure Correlation Premium (sc), CDS Pure Global Correlation Premium (scg).

\begin{tabular}{|c|c|c|c|c|}
\hline & A & BBB & $\mathrm{BB}$ & $\mathrm{CCC}$ \\
\hline \multicolumn{5}{|c|}{ Panel A } \\
\hline$b d$ & 0.258 & 0.267 & 0.256 & 0.27 \\
\hline$b d(\%)$ & $94 \%$ & $97 \%$ & $99.75 \%$ & $97.57 \%$ \\
\hline$b l$ & 0.0076 & -0.003 & $-2.9 \mathrm{e}^{\wedge}-4$ & $-3.7^{\wedge} \mathrm{e}-4$ \\
\hline$b l(\%)$ & $2.8 \%$ & $1.11 \%$ & $0.11 \%$ & $0.13 \%$ \\
\hline blg & -0.0019 & 0.0016 & $-2.9 e^{\wedge}-4$ & $4.2 \mathrm{e}^{\wedge}-3$ \\
\hline$b \lg (\%)$ & $0.72 \%$ & $0.5 \%$ & $0.11 \%$ & $1.5 \%$ \\
\hline$b c$ & -0.0047 & 0.0027 & $1.16 \mathrm{e}^{\wedge}-5$ & $1.6 e^{\wedge}-3$ \\
\hline$b c(\%)$ & $1.75 \%$ & $0.9 \%$ & $0.0045 \%$ & $0.59 \%$ \\
\hline$b c g$ & $1.9 \mathrm{e}^{\wedge}-4$ & $6.3 e^{\wedge}-4$ & $4.22 \mathrm{e}^{\wedge}-5$ & $4.5 \mathrm{e}^{\wedge}-4$ \\
\hline$b c g(\%)$ & $0.07 \%$ & $0.23 \%$ & $0.016 \%$ & $0.16 \%$ \\
\hline \multicolumn{5}{|c|}{ Panel B } \\
\hline$s d g$ & 1.65 & 98.5 & 54.2 & 99.87 \\
\hline$s d g(\%)$ & $49.87 \%$ & $50 \%$ & $50 \%$ & $50 \%$ \\
\hline$s l$ & -1.64 & -97.3 & -51.8 & -96.8 \\
\hline $\operatorname{sl}(\%)$ & $49.59 \%$ & $49.3 \%$ & $47.8 \%$ & $48.47 \%$ \\
\hline slg & -0.009 & -1.25 & -2.28 & -3 \\
\hline $\operatorname{slg}(\%)$ & $0.27 \%$ & $0.63 \%$ & $2.1 \%$ & $1.5 \%$ \\
\hline$s c$ & $2.1 \mathrm{e}^{\wedge}-4$ & $3.5 e^{\wedge}-3$ & $2 e^{\wedge}-4$ & $8 \mathrm{e}^{\wedge}-3$ \\
\hline$s c(\%)$ & $0.0064 \%$ & $0.0017 \%$ & $0 \%$ & $0.004 \%$ \\
\hline$s c g$ & $8.3 e^{\wedge}-3$ & $7.7 e^{\wedge}-3$ & $6.03^{\wedge}-4$ & $5.7 e^{\wedge}-3$ \\
\hline $\operatorname{scg}(\%)$ & $0.25 \%$ & $0.0039 \%$ & $0 \%$ & $0.0029 \%$ \\
\hline
\end{tabular}




\section{Table 5: VECM Analysis}

In this table, we report our results of the cointegration analysis. We study the cointegration between $b d$ and $s d g$ (i.e credit risk premia), bla and sla (i.e liquidity risk premia) and finally $b c a$ and $s c a$ (i.e correlation premia) where $b l a$ is the average of $b l$ and $b l g$, sla is the average of $s l$ and $s l g, b c a$ represents the average of $b c$ and $b c g$ and $s c a$ the average of $s c$ and $s c g$. We first test for stationarity using Augmented Dickey Fuller (ADF) test. If the series are non-stationary we estimate the Johansen Vector Error Correction Model (VECM) in order to study the long run relationship between the premia and the short term deviations (i.e the adjustment speed). We present the maximum likelihood estimation of the unnormalised cointegrated vector (Coint. Coeff) and the vector of adjustment (Speed Adj) parameters. On the other hand, if the series are not cointegrated we apply the Granger-Causality (GC) test in order to find which market leads the other in terms of price discovery. When the F-stat is significant this means that we cannot reject the fact that the independent variable cannot granger cause the dependent variable. In our analysis, we split our sample in two periods (before and during crisis). Subinvestment Grade refers to the average of rating BBB, BB and CCC, investment grade to rating A. NA means Non-Available. ${ }^{*}, * *$ and $* * *$ refers to $10 \%, 5 \%$ and $1 \%$ significance level of the t-statistic.

$\triangle b d \quad \triangle s d g \quad \triangle b l a \quad \triangle s l a \quad \triangle b c a \quad \triangle s c a$

Panel A: Subinvestment Grade (before crisis)

$\begin{array}{ccccccc}\text { Coint. Coeff } & \text { NA } & \text { NA } & \text { NA } & \text { NA } & 1^{* * *} & 13.2^{* * *} \\ \text { Speed Adj } & \text { NA } & \text { NA } & \text { NA } & \text { NA } & 0.0064 & -0.071 \\ \text { GC (F-stat) } & 0.73 & 7.94^{*} & 1.64 & 0.4 & \text { NA } & \text { NA }\end{array}$

Panel B: Investment Grade (before crisis)

$\begin{array}{ccccccc}\text { Coint. Coeff } & \text { NA } & \text { NA } & \text { NA } & \text { NA } & -0.14^{* * *} & -1.84^{* * *} \\ \text { Speed Adj } & \text { NA } & \text { NA } & \text { NA } & \text { NA } & 0.5 & 0.01 \\ \text { GC (F-stat) } & 0.59 & 1.95 & 2.07 & 5.38^{*} & \text { NA } & \text { NA }\end{array}$

Panel C: Subinvestment Grade (During crisis)

$\begin{array}{ccccccc}\text { Coint. Coeff } & \text { NA } & \text { NA } & 10.7^{* *} & 0.028^{* *} & 0.048^{* * *} & -0.041^{* * *} \\ \text { Speed Adj } & \text { NA } & \text { NA } & -0.61 & 0.0003 & -0.007 & -0.6 \\ \text { GC (F-stat) } & 1.83 & 1.37 & \text { NA } & \text { NA } & \text { NA } & \text { NA }\end{array}$

Panel D: Investment Grade (During crisis)

\begin{tabular}{ccccccc} 
Coint. Coeff & NA & NA & NA & NA & $0.01^{* *}$ & $0.98^{* *}$ \\
Speed Adj & NA & NA & NA & NA & -1.01 & -0.62 \\
GC (F-stat) & 0.40 & 2.05 & $16.2^{*}$ & $5.18^{*}$ & NA & NA \\
\hline
\end{tabular}

